\title{
Review \\ Mutational Diversity in the Quinolone Resistance-Determining Regions of Type-II Topoisomerases of Salmonella Serovars
}

\author{
Aqsa Shaheen ${ }^{1, *}$, Anam Tariq ${ }^{2}$, Mazhar Iqbal ${ }^{2}$, Osman Mirza $^{3}$, Abdul Haque ${ }^{4}$, Thomas Walz ${ }^{5}$ \\ and Moazur Rahman ${ }^{6, *}$ (D)
}

check for updates

Citation: Shaheen, A.; Tariq, A.; Iqbal, M.; Mirza, O.; Haque, A.; Walz, T.; Rahman, M. Mutational Diversity in the Quinolone ResistanceDetermining Regions of Type-II Topoisomerases of Salmonella Serovars. Antibiotics 2021, 10, 1455. https://doi.org/10.3390/ antibiotics 10121455

Academic Editor: Maria Teresa Mascellino

Received: 30 September 2021 Accepted: 24 November 2021 Published: 26 November 2021

Publisher's Note: MDPI stays neutral with regard to jurisdictional claims in published maps and institutional affiliations.

Copyright: (c) 2021 by the authors. Licensee MDPI, Basel, Switzerland. This article is an open access article distributed under the terms and conditions of the Creative Commons Attribution (CC BY) license (https:// creativecommons.org/licenses/by/ $4.0 /)$.
1 Department of Biochemistry and Biotechnology, Hafiz Hayat Campus, University of Gujrat, Gujrat 50700, Pakistan

2 Drug Discovery and Structural Biology Group, Health Biotechnology Division, National Institute for Biotechnology and Genetic Engineering (NIBGE), Faisalabad 38000, Pakistan; anamtariq.biotech@gmail.com (A.T.); mazhar@nibge.org (M.I.)

3 Department of Drug Design and Pharmacology, Faculty of Health and Medical Sciences, University of Copenhagen, 2200 Copenhagen, Denmark; om@sund.ku.dk

4 Human Infectious Diseases Group, Akhuwat First University, Faisalabad 38000, Pakistan; haque.hameed@akhuwat.org.pk

5 Laboratory of Molecular Electron Microscopy, Rockefeller University, New York, NY 10065, USA; twalz@rockefeller.edu

6 School of Biological Sciences, Quaid-I-Azam Campus, University of the Punjab, Lahore 54590, Pakistan

* Correspondence: aqsa.shaheen@uog.edu.pk (A.S.); moazur.rahman@fulbrightmail.org (M.R.); Tel.: +92-53-3643112-187 (A.S.); +92-42-35953122 (M.R.)

Abstract: Quinolone resistance in bacterial pathogens has primarily been associated with mutations in the quinolone resistance-determining regions (QRDRs) of bacterial type-II topoisomerases, which are DNA gyrase and topoisomerase IV. Depending on the position and type of the mutation (s) in the QRDRs, bacteria either become partially or completely resistant to quinolone. QRDR mutations have been identified and characterized in Salmonella enterica isolates from around the globe, particularly during the last decade, and efforts have been made to understand the propensity of different serovars to carry such mutations. Because there is currently no thorough analysis of the available literature on QRDR mutations in different Salmonella serovars, this review aims to provide a comprehensive picture of the mutational diversity in QRDRs of Salmonella serovars, summarizing the literature related to both typhoidal and non-typhoidal Salmonella serovars with a special emphasis on recent findings. This review will also discuss plasmid-mediated quinolone-resistance determinants with respect to their additive or synergistic contributions with QRDR mutations in imparting elevated quinolone resistance. Finally, the review will assess the contribution of membrane transporter-mediated quinolone efflux to quinolone resistance in strains carrying QRDR mutations. This information should be helpful to guide the routine surveillance of foodborne Salmonella serovars, especially with respect to their spread across countries, as well as to improve laboratory diagnosis of quinolone-resistant Salmonella strains.

Keywords: Salmonella; fluoroquinolones; quinolone resistance-determining regions (QRDRs); food-borne pathogens; plasmid-mediated quinolone resistance (PMQR); DNA gyrase; topoisomerase IV; typhoidal Salmonella; non-typhoidal Salmonella (NTS)

\section{Introduction}

'Quinolones' are a class of bactericides that include all synthetic drugs containing a quinolone or naphthyridone nucleus [1]. Quinolones exert their antibacterial effect by inhibiting bacterial DNA synthesis. The first synthetic quinolone, nalidixic acid, was introduced in 1962 to treat urinary tract infections [2]. Nalidixic acid and related firstgeneration antibiotics were only active against Gram-negative bacteria. Efforts to develop broad-spectrum antibacterial drugs by modifying nalidixic acid resulted in the introduction 
of "fluoroquinolones" (FQs) in 1980, which feature a fluorine atom at position C-6 of the quinolone ring [2] (Figure 1). While norfloxacin was the first FQ, used to treat urinary tract infections, ciprofloxacin, which was introduced in the United States in 1987, was widely prescribed to also treat various other infections. Ciprofloxacin was found to be very effective against Gram-negative bacilli, but it was less active against Gram-positive bacteria [3]. In 1991, another FQ analogue was introduced, ofloxacin, which was particularly effective in treating systemic infections [4].<smiles>[R]n1ccc(=O)c2ccccc21</smiles>

Quinolone nucleus<smiles>[R]n1ccc(=O)c2cccnc21</smiles>

Naphthyridone nucleus<smiles>[R7]c1c(F)c([R])c2c(=O)c(C(=O)O)cn([R7])c2c1[Y]</smiles>

Fluoroquinolone nucleus

Figure 1. Structures of the quinolone, naphthyridone, and fluoroquinolone nuclei. ' $R$ ' denotes an alkyl group, ' $\mathrm{X}$ ' denotes a small substituent, such as $\mathrm{F}, \mathrm{Cl}$, or $\mathrm{CH}_{3} \mathrm{O}^{-}$.

It should be noted that not all cases of salmonellosis are treated with quinolones. The reason is that it is generally not recommended to use antibiotics to treat non-typhoidal Salmonella (NTS) gastroenteritis, because it is usually self-limiting [5]. However, FQs are prescribed if Salmonella gastroenteritis is anticipated to aggravate the other disorders of a patient, such as cardiovascular diseases, immunosuppressed conditions, and malignant diseases. Treatment with FQ is also recommended when patients show symptoms of severe sepsis, such as high body temperature, impaired kidney function, and systemic toxicity [5]. FQs, particularly ciprofloxacin and ofloxacin, are excellent drugs to cure typhoidal and non-typhoidal salmonellosis as well as to clear asymptomatic bacillus carriers of the bacteria [6-8].

However, widespread use of FQs has resulted in the appearance of chromosomal and plasmid-mediated resistance mechanisms. This review focuses on FQ resistance caused by target-site mutations, i.e., mutations in the quinolone resistance-determining regions (QRDRs; see below) of type-II topoisomerases.

\section{Mode of Action of Fluoroquinolones and QRDRs}

The bactericidal mode of action of FQs is through the inhibition of the bacterial DNAsynthesis machinery, specifically by interfering with the type-II topoisomerases DNA gyrase and topoisomerase IV [1]. The physiological role of DNA gyrase is to introduce negative supercoiling in DNA [9], so that a DNA molecule, which can be 1000 to $10,000 \mu \mathrm{m}$ long, can be sufficiently compacted to fit inside the limited volume of a bacterium [10]. The functional unit of bacterial DNA gyrases is a tetramer, consisting of two GyrA and two GyrB subunits [11]. The GyrA subunit is responsible for breaking and resealing the target DNA strand and the GyrB subunit provides the required energy through ATP hydrolysis [11]. Topoisomerase IV, which is critical for proper daughter chromosome separation during replication, is also a tetramer and consists of two ParC and two ParE subunits [10-12]. During replication, the ParC subunit co-localizes with the replisome [12], which requires a ParE subunit with an active catalytic ATPase site [13]. The GyrA subunit of DNA gyrase is homologous to the ParC subunit of topoisomerase IV, and the GyrB subunit to the ParE subunit [14].

FQ antibiotics inhibit type-II topoisomerases after they bind to DNA and form a transient complex, in which the enzyme's active-site tyrosine (Tyr) residue forms a covalent bond with a DNA phosphate ester, thus hindering the resealing process and resulting in the accumulation of double-stranded DNA fragments $[15,16]$. DNA gyrase is usually 
referred to as the primary target of quinolones in Gram-negative pathogens such as E. coli and Salmonella [13,17], whereas topoisomerase IV is considered to be the primary target of quinolones in Gram-positive bacteria such as Streptococcus. However, there are many exceptions to this rule. For example, in some Gram-positive species, FQs target both DNA gyrase and topisomerase IV [18,19], and in other species, different quinolones have distinct primary targets [16].

Quinolone resistance is centered on a small stretch of amino acid residues, commonly referred to as the quinolone resistance-determining regions (QRDRs), of bacterial DNA gyrase and topoisomerase IV. These QRDRs are hotspots for mutations that result in quinolone resistance.

Initially, Yoshida et al. defined the QRDR of GyrA from the alanine (Ala) at position 67 to the glutamine (Gln) at position 106 (numbering for the E. coli protein) [20] (Figure 2A) and that of GyrB from aspartate (Asp) 426 to lysine (Lys) 447 [21] (Figure 2B). Some researchers described the QRDR of Salmonella GyrA to contain amino acids 67 to 122 [22]. The QRDR of ParC encompasses the residues between Ala64 and Gln103 (Figure 2C) and that of ParE those between Asp420 and Lys441 (Figure 2D).
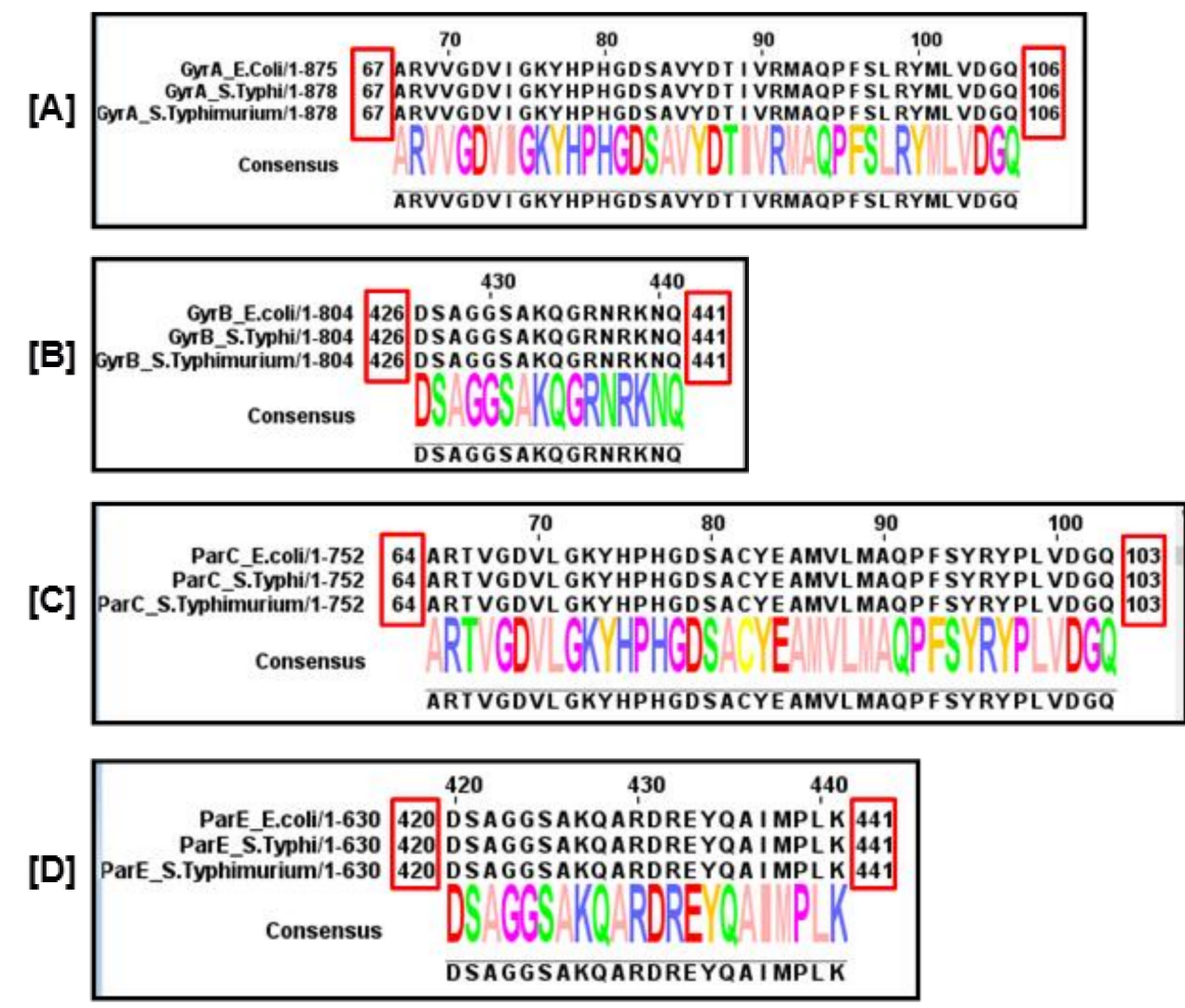

Figure 2. Amino acid sequence alignment for the QRDR of E. coli, S. Typhi and S. Typhimurium homologs. (A); GyrA QRDR (Ala67-Gln106) (B); GyrB QRDR (Asp426-Lys447) (C); ParC QRDR (Ala64 to Gln103) (D); ParE QRDR (Asp420-Lys441). The alignment was performed with MUSCLE using Jalview [23]. The complete sequence alignment of all these genes is shown in supplementary Figures S1-S4 for GyrA, GyrB, ParC, and ParE, respectively.

The Genbank accession numbers of all these genes are given in Table 1. 
Table 1. Genbank accession numbers of type-II topoisomerases used for sequence alignment.

\begin{tabular}{ccccc}
\hline \multirow{2}{*}{ Bacteria } & GyrA & GyrB & ParC & ParE \\
\cline { 2 - 5 } & \multicolumn{4}{c}{ Genbank Accession Numbers } \\
\hline E. coli O157:H7 str. EDL933 & AAG57360.1 & AAG58896.1 & AAG58155.1 & AAG58169.1 \\
S. Typhi str. Ty2 & AAO68297.1 & AAO71180.1 & AAO70639.1 & AAO70645.1 \\
S. Typhimurium str. LT2 & AAL21173.1 & AAL22694.1 & AAL22048.1 & AAL22055.1 \\
\hline
\end{tabular}

According to Afzal et al., QRDRs include: amino acids Asp36 to Gly151 of GyrA, Gly405 to Glu520 of GyrB, al46 to Leu133 of ParC, and Glu449 to Ile529 of ParE [24]. One should be aware, however, that further research is likely to expand the QRDR regions. In fact, the QRDR of GyrA has already been proposed to include the residue at position 51, because of its critical role in quinolone resistance [25]. Similarly, the proposed involvement of arginine (Arg) 121 in the formation of a salt bridge when GyrA interacts with ciprofloxacin [26] prompted some researchers to expand its QRDR to residues downstream of Gln106 [22,24]. Likewise, complete sequencing of the gyr $A$ gene of quinolone-resistant isolates has implicated mutations outside the QRDR in FQ resistance [27].

In the last ten years, a growing number of publications addressed the issue of quinolone resistance among clinical and veterinary isolates of Salmonella [28-31]. However, there is currently no comprehensive overview that describes the diversity of mutations in QRDRs of different Salmonella serovars and their relationship with plasmid-mediated quinolone resistance (PMQR) determinants. This review aims to fill this gap and to collate available information, with a focus on recent findings, to provide a snapshot of current QRDR mutations and their relevance to circulating strains of different Salmonella serovars.

\section{Known Mechanisms of Quinolone Resistance}

Selection pressures imposed by antibiotics such as quinolones and the evolutionary principle of survival of the fittest have led pathogens, including Salmonella, to develop a variety of evasion mechanisms [32-34]. Salmonella express chromosomally and plasmidencoded proteins that protect them against quinolones. In terms of chromosomally encoded proteins, mutations can alter the drug targets [35-37] or affect local and global repressors that result in down-regulated expression of outer membrane porins $[38,39]$ or up-regulated expression of inner membrane efflux transporters [40-43]. These defense mechanisms can be further enhanced by transferable resistance elements residing on plasmids.

Plasmid-borne quinolone-resistance determinants work through three distinct mechanisms. First, Qnr proteins [44], a family of pentapeptide repeat proteins [45,46], interfere with the action of FQs on type-II topoisomerases either by reducing the formation of replication forks, thus reducing the recruitment of topoisomerases to DNA, or, if the replication fork has already formed, by occupying the sites in the replication fork where quinolones would bind [47]. Based on their sequence similarity, Qnr proteins have been further divided into the qnrA [44], qnrB [48], qnrC [49], qnrD [33], QnrS [50] and QnrCV [51] families [13]. Second, the aminoglycoside-(6)-N-acetyltransferase encoded by the aac ( $\left.6^{\prime}\right)-\mathrm{Ib}-\mathrm{cr}$ gene, which differs from that encoded by the $a a c\left(6^{\prime}\right)-I b$ gene by the presence of two point mutations, Trp102Arg and Asp179Tyr, N-acetylates and thus inactivates quinolones [52]. Third, efflux transporters, such as OqxAB [53], QepA1 [54,55], QepA2 [56] and QepA3 [57], contribute to quinolone resistance by extruding antibiotics from the bacteria.

The relative capacity of the various mechanisms to confer FQ resistance varies. Ciprofloxacin is usually chosen as a representative FQ in minimum inhibitory concentration (MIC) assays to evaluate the resistance level of clinical isolates. Clinical and laboratory standard institute (CLSI) guidelines [58] are followed to ensure a uniform classification of isolates showing ciprofloxacin resistance. According to these guidelines, resistant isolates have an MIC of 1-2 mg/L, isolates with intermediate susceptibility have an MIC of $0.12-0.5 \mathrm{mg} / \mathrm{L}$, and susceptible isolates have an MIC of $\leq 0.06 \mathrm{mg} / \mathrm{L}$. Measured in this way, chromosomally encoded efflux proteins increase the MIC of ciprofloxacin by a factor of 2 to 8 [59-61], and porin downregulation increases the MIC by a similar factor [62], whereas 
mutations in topoisomerases account for a 10- to 60-fold increase in the MIC, depending on the number and position of the mutations $[63,64]$. For plasmid-encoded proteins, the efflux pumps QepA and OqxAB increase the MIC of ciprofloxacin by a factor of 10 to 16 [53,55,65], Qnr proteins account for a 16- to 125-fold increase in the MIC [66], and the quinolone $\mathrm{N}$-acetylating enzyme is responsible for a 4-fold increase in the MIC [52].

\section{Mutations in the QRDRs of Salmonella Serovars}

Salmonella is a diverse genus, primarily divided into two species, S. enterica and S. bongori. S. enterica is further divided into six subspecies. S. enterica subsp. enterica (>1500 members) is the largest subspecies [67] and is of primary interest for public health. Members of S. enterica subsp. enterica have adapted to warm-blooded vertebrates (birds and mammals) [68] and these Salmonella serovars are the leading food-borne pathogens. Ciprofloxacin resistance in food-borne Salmonella has been reported worldwide [69]. Salmonella Enteritidis and Salmonella Typhimurium are the isolates identified in food that are most commonly implicated as the source of salmonellosis, and there have been numerous reports on mutations in the QRDRs of isolates. Other serovars are usually limited to certain geographical regions and are therefore less well surveilled. However, global travel and food import have substantially increased the risk of salmonellosis associated with less prevalent serovars. The current review covers the available information related to the Salmonella serovars listed in Table 2.

Table 2. List of Salmonella serovars analyzed for mutations in their QRDRs.

\begin{tabular}{ccc}
\hline & Salmonella enterica subsp. enterica & Discussed In \\
\hline Typhoidal Salmonella & Typhi & Section 4.1 \\
Non-typhoidal Salmonella & Paratyphi A, B and C & Section 4.1 \\
$($ NTS) & Enteritidis & Section 4.2 .2 \\
& Typhimurium & Section 4.2 .3 \\
& Hadar & Section 4.2 .4 \\
& Sentucky & Section 4.2 .5 \\
& Indiana & Section 4.2 .6 \\
& Infantis & Section 4.2 .7 \\
& Derby & Section 4.2 .8 \\
\end{tabular}

\subsection{Mutations in the QRDRs of Typhoidal Salmonella}

Typhoidal Salmonella, including S. Typhi and S. Paratyphi A-C, are a major cause of morbidity and mortality in developing countries and among travelers visiting areas where these pathogens are endemic [36]. The persistence of typhoidal Salmonella is mostly due to poor sanitation and unhygienic conditions but food handlers carrying typhoidal Salmonella have also been suggested to contribute to the high endemicity of typhoid fever $[70,71]$.

Analysis of QRDR mutations in $S$. Typhi isolates showed that reduced ciprofloxacin susceptibility in this serovar is most often caused by a substitution of Ser83 to phenylalanine (Phe) in GyrA (Table S1), a mutation that has been found worldwide [24,64,72-80] (Figures 3 and 4). Analysis of the literature from Asia, in particular from Southeast Asia, revealed that in India, Bangladesh, Pakistan and Nepal, the Ser83Phe substitution is the most prevalent mutation in ciprofloxacin-resistant $S$. Typhi isolates, with an MIC ranging from 0.9 to $3 \mathrm{mg} / \mathrm{L}$, and the Ser83Tyr substitution is the second most frequent mutation [24,64]. Most of these studies reported the absence of PMQR determinants. While it had been proposed earlier that Ser83 is an important site for imparting partial FQ resistance in S. Typhi and S. Paratyphi A [81], complete ciprofloxacin resistance requires double mutations in the QRDR of GyrA [35]. Complete ciprofloxacin resistance of $S$. Typhi in the absence of a double mutation in the gyr $A$ suggests that these isolates also acquired an active efflux transporter or have impaired outer membrane porins. This has been observed in an $S$. Typhi 
isolate from South Africa with an MIC of $4 \mathrm{mg} / \mathrm{L}$, which carried only a single substitution in a gyrA gene, namely Ser83Tyr, and the presence of $q n r S 1$, but also featured an efflux system that contributed to its ciprofloxacin resistance [82]. However, most of the studies examining ciprofloxacin resistance in $S$. Typhi have not investigated the contribution of all the possible resistance mechanisms (Table S1).

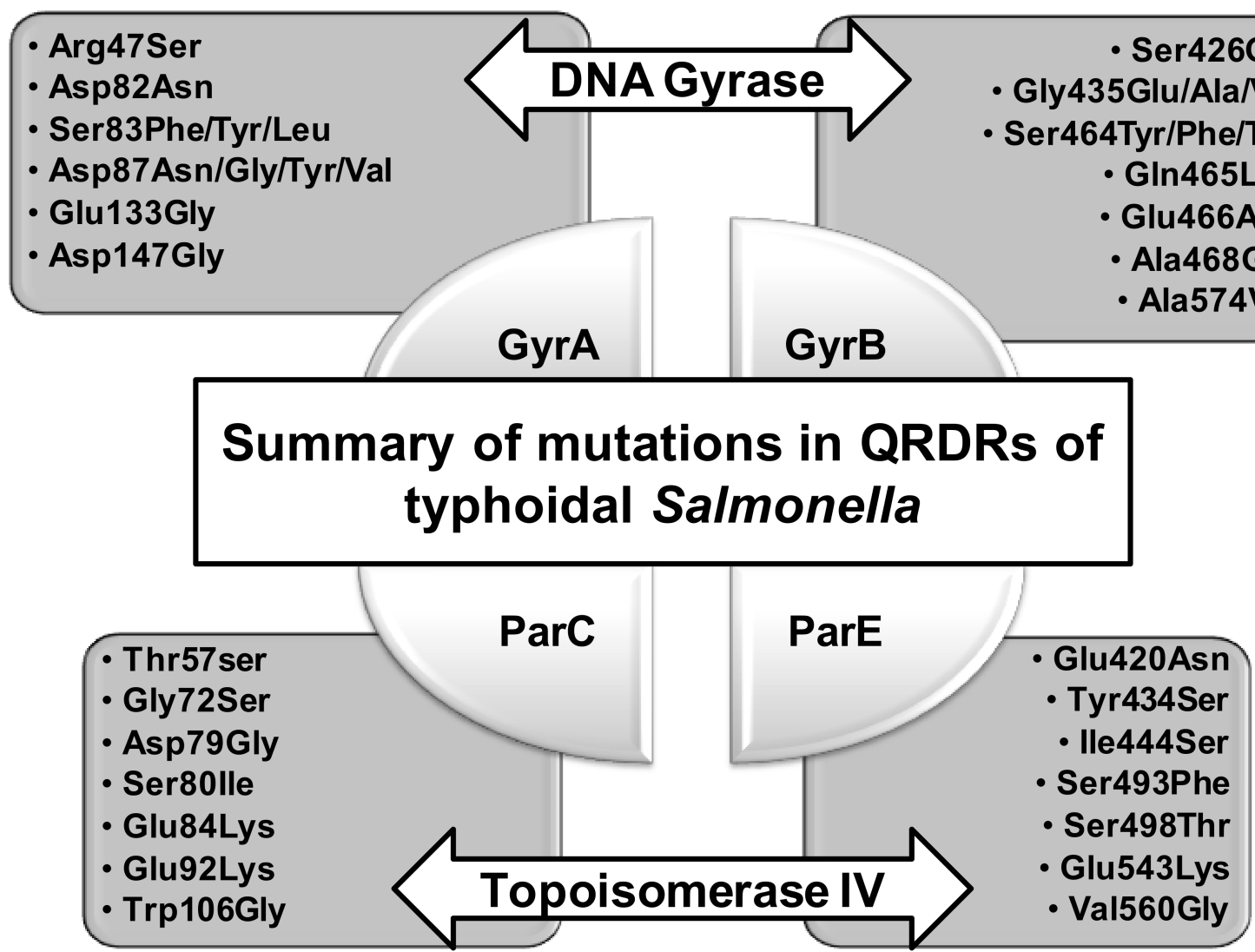

Figure 3. Mutations found in the QRDRs of DNA gyrase (GyrA and GyrB) and topoisomerase IV (ParC and ParE) of typhoidal Salmonella.

Gyr A_E.Coli/1-875 GyrA_S.Typhi/1-878 Gyt A_S.Typhimurium/1-878

Consensus 1 MSDLARE I TPVN I EEELKSSYLDYAMSVI VGRALPDVRD LL KPVHRRVLYAMNVLGNDWNKAYKKSARVVGDVIGKYHPH 80

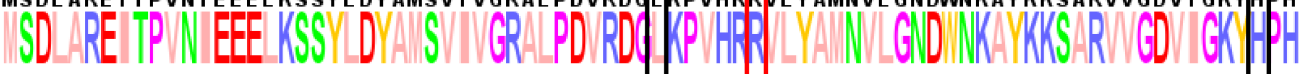
MSDLARE I TPVN I EEELKSSYL DYAMSVIVGRALPDVRD \& LKPVHR RLYAMNVLGNDWNKAYKKSARVVGDVIGKY HH
$* \quad * \quad 90$
100
120
130
140
150

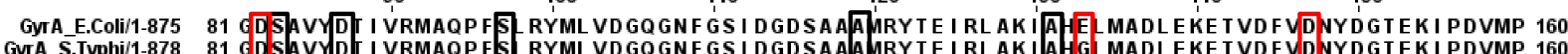

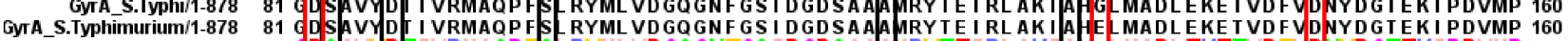

Consensu

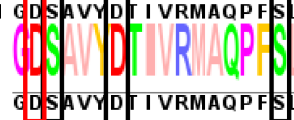

170

180

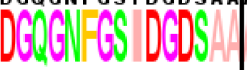

YML VDGQGNF GSI DGDSAAAARY

190

200

A

GyrA_E.Coli/1-875 161 T K I PNLL VNGSSG I AVGMAT I PPHNL TEV I NGCL AY I DDED I S I EGLMEH I PGPDFPT AA I I NGRRG I EEAYRT GRGKV 240 Gy

Consensus

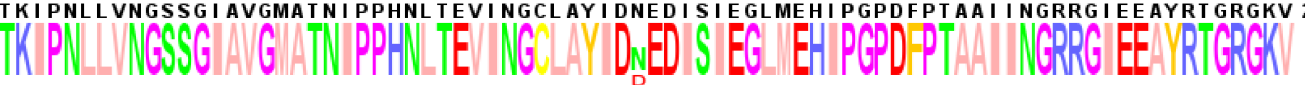

TKI PNLLVNGSSG I AVGMAT N I PPHNL TEVI NGCL AYI DNED I S I EGLMEHI PGPDFPT AAI I NGRRG I EE AYRT GRGKV

Figure 4. Summary of mutations found in GyrA. Red boxes indicate residues found to be mutated in typhoidal Salmonella. Black boxes indicate residues found to be mutated in non-typhoidal Salmonella (discussed below) and "** indicate residues found to be mutated in both. 
Of note, S. Typhi H58 strains generally seem to carry the Ser83Phe mutation in GyrA [83]. This strain is prevalent in Vietnam, India, Bangladesh, Pakistan, Laos and Nepal [83] and cases reported in China, France, Kenya and Japan can be linked to travel to these areas [72,75,84,85].

Another residue that has been found to be mutated in most studies is Asp at position 87. It has been found to be mutated into Asn, Gly, Tyr and Val [72,74,86] (Figure 3). Two independent studies reported ciprofloxacin-resistant isolates with two substitutions in GyrA, Asp87Val and Ser83Phe $[34,86]$. The Asp87Val substitution is rare and imparts resistance (Table S1). Koirala et al. were the first to describe this mutation and a comparison with already known double mutants, namely Ser83Phe/Asp87Asn and Ser83Phe/Asp87Gly, established that it was the Asp87Val mutation that was responsible for the increased ofloxacin resistance [86]. Another resistance-conferring substitution in GyrA, Asp87Tyr, is not commonly found in S. Typhi and has only been reported for isolates from Belgium [34] (Table S1). An additional uncommon mutation in S. Typhi is Ser83Leu [34,87]. A novel mutation reported for an isolate from Italy, Asp82Asn, was found not to confer resistance to ciprofloxacin [76].

In addition to the most frequently mutated GyrA residues in typhoidal Salmonella, Ser83 and Asp87, the Glu133Gly substitution, first identified only in S. Typhi and later also in $S$. Typhimurium, has also been suggested to confer ciprofloxacin resistance (Table S1). However, the wild-type residue at position 133 is controversial for S. Typhi, because an analysis of available GyrA sequences in GenBank shows that a Gly is more common in this position [88], and Ceyssens et al. reported that 50\% of Belgian S. Typhi isolates also have a Gly at this position [34]. Furthermore, Eibach et al. found that an S. Typhi isolate carrying only the Glu133Gly mutation was susceptible to ciprofloxacin with an MIC of $0.06 \mathrm{mg} / \mathrm{L}$ [89], implying that a Gly at this position does not confer resistance. Similar findings were made for isolates from Cambodia [90]. Another study on $S$. Typhi isolates collected in Iran reported that Ser83Phe/Gly133Glu double mutants were more susceptible to nalidixic acid than single Ser83Phe mutants [91]. An earlier study found an isolate from India with the identical double mutation in GyrA to be resistant to nalidixic acid [92], but this discrepancy was later resolved by the identification of an efflux activity conferring resistance to this strain [91].

Mutations in GyrB occur far less frequently in S. Typhi, but occur for Gly435 [76], Ser464 [72,93], Gln465 [72], Glu466 [72], Ala468 [72] and Ala574 [34] (Table S1) (Figure 5). The Ser464Phe mutation is particularly important for conferring a non-classical resistance phenotype, in which strains are susceptible to nalidixic acid but display an intermediary susceptibility to ciprofloxacin [72]. The Gln465Leu, Glu466Asp, and Ala468Glu mutations do not confer ciprofloxacin resistance [72]. Mutations in ParC are even less common, with the preferred sites being Thr57, which is almost always mutated to Ser, and Ser80, which can be substituted by an Arg or Ile, with the latter mutation being found in S. Typhi (Table S1). Eaves et al. suggested that the Thr57Ser mutation reduces the binding affinity for quinolone, as a result of the smaller Ser side chain [94], but Qian et al. described it as a compensatory mutation that actually caused the Salmonella isolates to become susceptible to ciprofloxacin [95]. Other uncommon ParC mutations in S. Typhi include Glu92Lys [85] and Trp106Gly [96]. The presence of a Glu residue at position 92 needs to be further investigated, because our current survey found this position to be usually occupied by a proline (Figure 6). Mutations in ParE were reported for isolates from France and Italy that were collected from travelers returning from India. The Asp420Asn mutation appears to increase ciprofloxacin susceptibility [72] (Figure 7), isolates carrying only a Ser83Phe substitution are more resistant to ciprofloxacin, and the effect of the Ser493Phe mutation in ParE awaits further investigation [76]. 
450

$460 \quad *$

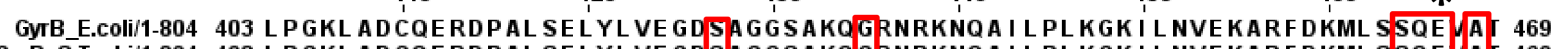
GyrB_S.Typhi/1-804 403 LPGKLADCQERDPALSELYLVEGDSAGGSAKOGRNRKNQA I LPLGKILNVEKARFDKMLSSQEVAT 469 GyrB_S.Typhimurium/1-804 403 LPGKLADCQERDPALSELYLVEGDSAGGSAKOGRNRKNQA I L PLKGK I L NVEKARFDKML SSQEVA 469

Consensus

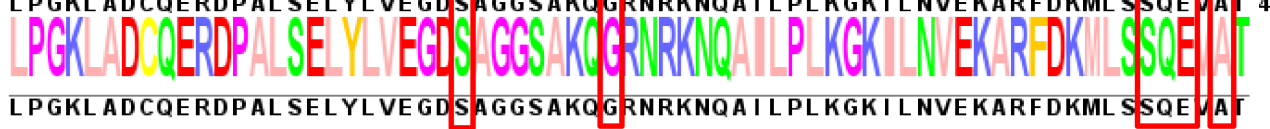
470
480
490
500
510
520
530

GyrB_E.coli/1-804 470 I T AL GCG I GRDEYNPDKLRYHS I I I MT D ADVDGSH I RT L L L T F FYRQMPE I VERGHVY I AQPPLYK 536 GyrB S.Typhi/1-804 470 LI T AL GCG I GRDEYNPDKLRYHS I I I MT D ADVDGSH I RT LL L T F FYRQMPE I VERGHVY I AQPPLYK 536 GyrB_S.Typhimurium/1-804 470 L I T AL G CG I GRDEYNPDKLRYHS I I I MT D ADVDGSH I RT L L T F FYRQMPE I VERGHVY I AQPPLYK 536

Consensus

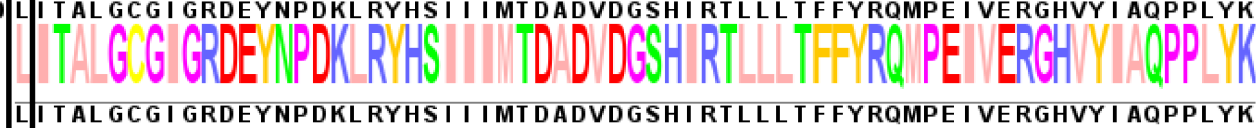
540
550
560
570
580
590
600

GyIB E.coli/1-804 537 VKKGKQEQY I KDDE AMDQYQ I S I ALDGATLHT NÁSAPA AGEAL'EKL VSEYNATQKMI NRMERRYPK 603 GyrB_.Coli-804 537 VKKGKQEQY I KDDEAMDQY I I ALDGATLHANAHAPA SGEALEKLVSEYNATQKMI GRMERRFPK 603 GyrB_S.Typhimurium/1-804 537 VKKGKQEQY I KDDEAMDQYQ I S I ALDGAT L HANAHAPAESGEALEKLVSEYNATQKM I GRMERRFPK 603

Consensus

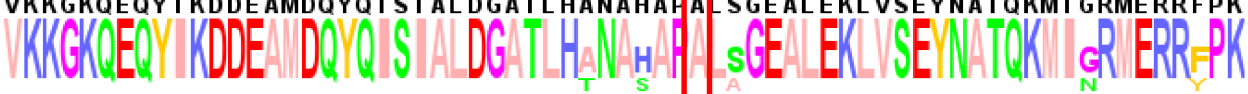

VKKGKQEQY I KDDE AMDQYQ I S I ALDGAT LHANAHAPA SGE ALEKLVSEYNAT QKM I GRMERRFPK

Figure 5. Summary of mutations found in GyrB. Red boxes indicate residues found to be mutated in typhoidal Salmonella. Black boxes indicate residues found to be mutated in non-typhoidal Salmonella (discussed below) and "* indicate residues found to be mutated in both.

10

ParC_E.coli/1-752 ParC_S.Typhi/1-752 ParC_S.Typhimurium/1-752

Consensus Parc_S.Typhimurium/1-752

Consensus

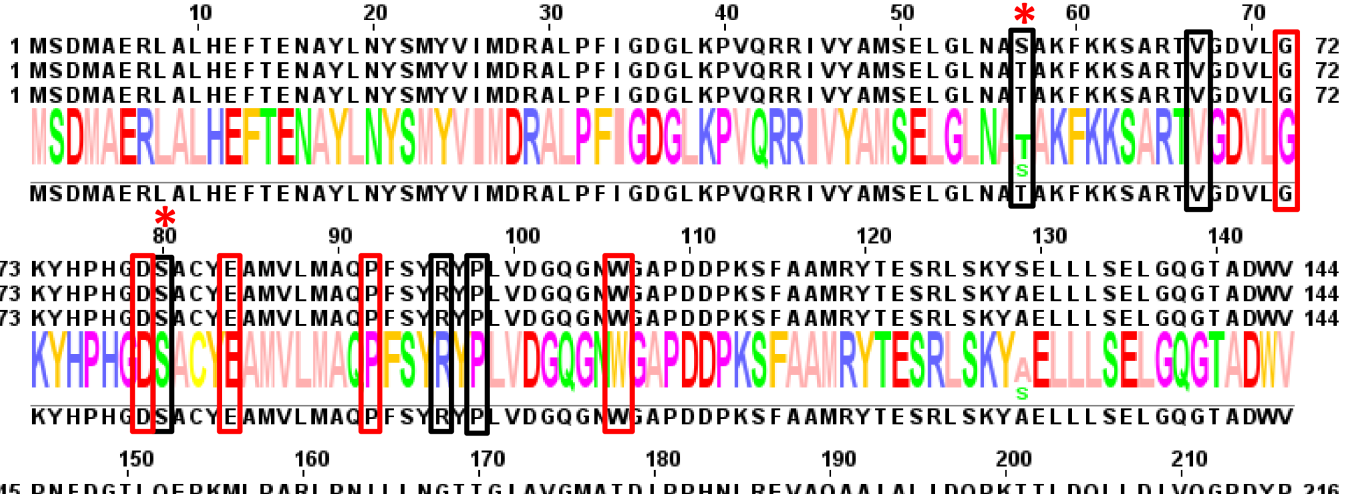

ParC E.coli/1-752 145 PNFDGTLQEPKML PARLPN I L L NGT T G I AVGMAT D I PPHNLREVAQAA I AL I DQPKT TLDQLLD I VQGPDYP 216 Parc s.Typhi/1-752 145 PNFDGTMQEPKML PARL PN I LLNGT T I AVGMAT D I PPHNLREVAKA A I TL I EQPKT TL DQLLD I VQGPDYP 216 Parc_s.Typhimurium/1-752 145 PNFDGTMQEPKMLPARLPN I LL NGT T G I AVGMAT D I PPHNLREVAKAA I TL I EQPKT TLDQLLD I VQGPDYP 216

Consensus

PNFDGTMQEPKML PARLPN I LLNGT T G I AVGMAT D I PPHNLREVAKAA I TL I EQPKT TLDQLLDIVQGPDYP

Figure 6. Summary of mutations found in ParC. Red boxes indicate residues found to be mutated in typhoidal Salmonella. Black boxes indicate residues found to be mutated in non-typhoidal Salmonella (discussed below) and "** indicate residues found to be mutated in both.

Mutations in S. Paratyphi strains are not well documented. Among the three strains causing paratyphoid fever, $S$. Paratyphi A is more prevalent and is therefore comparatively better studied in terms of epidemiology and resistance mechanisms. In 2010, a large-scale outbreak of paratyphoid fever was reported in China [97], and in 2013, another outbreak occurred among Japanese travelers returning from Cambodia [98]. An investigation using whole-genome sequencing revealed that a strain carrying the Ser83Phe mutation in GyrA originated in Cambodia and was then spread by travelers into other countries [71,97]. The Ser83Tyr and Asp87Asn mutations were the second and third most abundant mutations found in this study but occurred significantly less frequently than Ser83Phe [71]. S. Paratyphi A, B and C strains with mutations in their QRDRs have been reported for isolates from Europe [34], Africa [99] and Asia [91,95,100]. With only few exceptions, all these isolates carried a single mutation in GyrA either at position 83 or 87 (Table S1). Double mutations were reported for Iranian isolates with S. Paratyphi B carrying Arg47Ser and Asp87Gly and S. Paratyphi C carrying Asp147Gly and Ser83 Phe [91]. Arg47Ser and Asp147Gly are 
novel mutations and their contribution to conferring ciprofloxacin resistance is not yet clear. One of the S. Paratyphi A isolates with high ciprofloxacin resistance, i.e., an MIC of $32 \mathrm{mg} / \mathrm{L}$, has a double mutation in GyrA, Ser83Phe and Asp87Gly [100]. This isolate was found to be negative for the presence of PMQR genes but the contribution of efflux was not investigated. An earlier study of an S. Paratyphi A isolate from Japan showed an unusually high ciprofloxacin resistance with an MIC of $128 \mathrm{mg} / \mathrm{L}$. The basis of this very high resistance was identified as double mutations in GyrA, Ser83Phe and Asp87Asn, together with a Glu84Lys mutation in parC [101]. Recently, S. Typhi and S. Paratyphi B isolates from Jiangsu Province of China have been reported to carry many novel mutations in GyrB, ParC and ParE (Table S1) [95]. However, their relevance for ciprofloxacin resistance awaits further study. Moreover, the nature of the wild-type residue at position 498 requires further analysis, our sequence alignment of a representative typhoidal Salmonella strain, i.e., S. Typhi str. Ty2, with a representative NTS strain, i.e., S. Typhimurium str. LT2 and E. coli O157:H7 str. EDL933 suggests that the wild-type residue at this position is Ile (Figure 7), and not Ser as has been stated before [95].

$$
\begin{array}{rrrrr}
340 & 350 & 360 & 370 & 390
\end{array}
$$

ParF E.coli/1-630 331 GQT KERL SSRQC A A FVSGVVKD A F I LWL NQNVQAAELLAEMA I SSAQRRMRA AKKVVRKKL T S GPA 396 ParE S.Typhi/1-630 331 GQT KERL S SRQ CAAFVSGVVKDAF SLWL NQNVQAAEQL AEMA I AS AQRRL RAAKKVVRKKL T SGPA 396 ParE_S.Typhimurium/1-630 331 GQT KERLSSRQCAAFVSGVVKDAFSLWL NQNVQAAEQLAEMA I ASAQRRLRAAKKVVRKKL T S GPA 396

Consensus

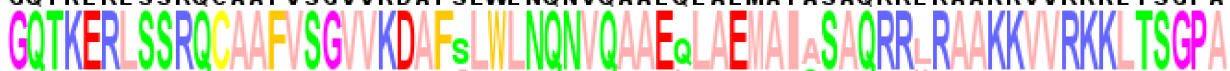
GQT KERL SSRQC A A FVSGVVKD A F SLWL NQNVQA AEQL AEMA I ASAQRRL RA AKKVVRKKL TSGPA
400
410
420
430
440
450
460

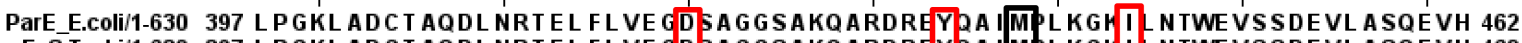
ParE_S.Typhi/1-630 397 L PGKL ADCT AQDL NRT EL FL VE GDSAGGSAKQARDREYQA IMPL KGH I NTWEVSSDEVLASQEVH 462 ParE_S.Typhimurium/1-630 397 LPGKLADCT AQDL NRT EL FLVE GDSAGG AKQARDREYQA IMPL KGH I NTWEVSSDEVLASQEVH 462

Consensus

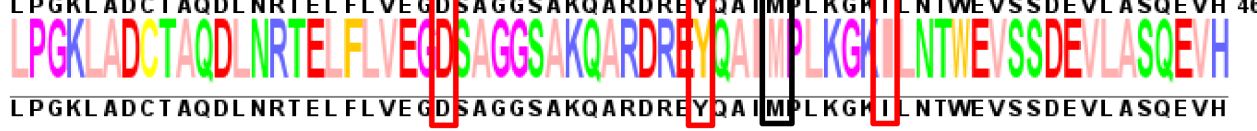
470
480
500
510
520

490

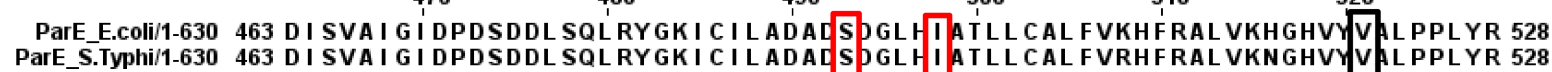
ParE_S.Typhimurium/1-630 463 D I SVA I G I DPD SDDL SQLRYGK I C I L ADADS DGL I ATLL CAL FVRHFRAL VKNGHVYVAL PPLYR 528

Consensus

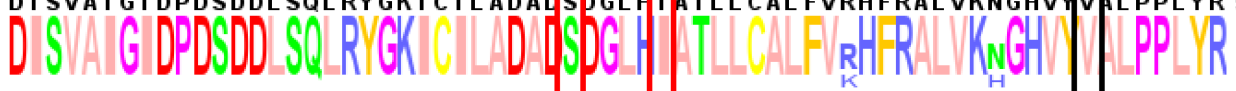

D I SVA I G I DPDSDDLSQLRYGKI CILADALSSGLH I ATLLCALFVRHFRALVKNGHVYVALPPLYR

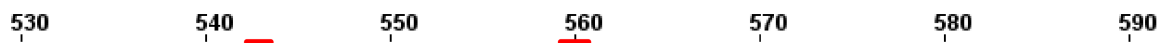

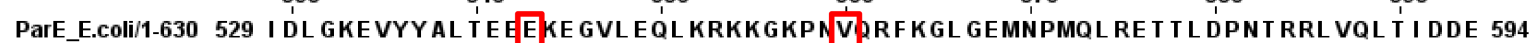

ParE S.Typhi/1-630 529 I DL GKEVYYAL T E EE KA GVLEQL KRKKGKPN VDRF KGL GEMNPMQLRE T L DPNTRRL VQL T I SDE 594 ParE_S.Typhimurium/1-630 529 I DL GKE VYYAL T E EE KA GVLEQL KRKKGKPN V 2 RF KGL GEMNPMQLRE T T L DPNT RRL VQL T I SDE 594

Consensus

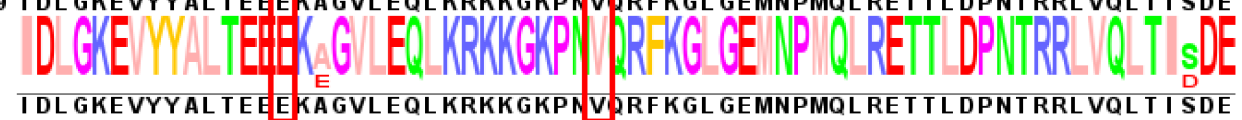

600

610

620

630

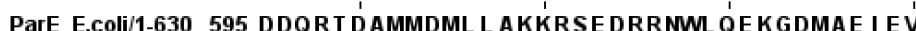

ParE S.Typhi/1-630 595 DDQRT NAMMDML AKKRSEDRRNWL QEKGDLADLDV ParE_S.Typhimurium/1-630 595 D DQR T N AMMDML L A KKRSE DRRNWL QE KGDL A DL DV

Consensus

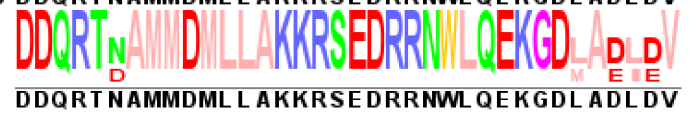

Figure 7. Summary of mutations found in ParE. Red boxes indicate residues found to be mutated in typhoidal Salmonella. Black boxes indicate residues found to be mutated in non-typhoidal Salmonella (discussed below).

The diverse mutations found in the QRDRs of typhoidal Salmonella are summarized in Figure 3. These sites of mutations for $g y r A, g y r B$, parC and parE are also explained in the aligned sequences in Figures 4-7, respectively.

The PMQR genes detected in $S$. Typhi isolates carrying QRDRs mutations are qnrS1 and qnrB2 (Table S1). The qnrS1 gene has been reported in isolates from different regions $[82,85,102]$, but its origin could be traced back to Southeast Asia. It should be noted that quinolone efflux is rarely investigated and this resistance mechanism is thus likely underappreciated. According to Adachi et al., the different MICs of isolates with the 
same QRDR mutation can be explained by the involvement of other quinolone-resistance mechanisms [101], for example, for $S$. Typhi isolates with the Ser83Phe substitution that show MICs from 0.19 to $3 \mathrm{mg} / \mathrm{L}[24,34,72,75,100]$ (Table S1). Taken together, S. Typhi and $S$. Paratyphi A appear to respond to ciprofloxacin pressure predominantly by adopting the Ser83Phe mutation in GyrA. Since S. Paratyphi B and C are less prevalent, large-scale studies in endemic areas are needed to evaluate their serovar-specific mutation resulting from antibiotic pressure.

\subsection{Mutations in the QRDRs of Non-Typhoidal Salmonella}

Non-typhoidal Salmonella (NTS) are most often contracted through the consumption of contaminated food and water. While the thermal processing of food is considered to be an effective method to eliminate NTS, NTS infections caused by the consumption of thermally treated food are still reported around the globe. The predominant serovars of foodborne Salmonella are $S$. Typhimurium, S. Enteritidis, S. Newport, $S$. Indiana, S. Kentucky, and $S$. Virchow $[103,104]$. There have been many studies on mutations in the QRDRs of $S$. Enteritidis and $S$. Typhimurium, because of their universal prevalence and because they cause most gastroenteritis-associated infections. Other Salmonella serovars are less often associated with gastroenteritis and so there are less studies on their QRDR mutations.

\subsubsection{Salmonella Enteritidis (S. Enteritidis)}

$S$. Enteritidis is the prime cause for egg-borne NTS infections in developed countries [29,105]. A study by Lunn et al., on clinical isolates of $S$. Enteritidis in Barcelona, found that the Asp87Tyr substitution in GyrA is the predominant mutation in $S$. Enteritidis isolates [106]. Another study from Spain also found this mutation in the majority of $S$. Enteritidis isolates, which exhibited MICs of ciprofloxacin ranging from 0.03 to $2 \mathrm{mg} / \mathrm{L}$ [107]. Our literature review finds that Asp87Tyr is also the predominant substitution in $S$. Enteritidis isolates from Malaysia [108,109], Korea [110,111], Africa [89], Brazil [112,113] Belgium [34], Japan [114] and Thailand [115] (Table S2).

The Asp87Tyr substitution is dominant in isolates from different origins, but substitutions to Gly and Asn are found at a lower frequency [89,91,115-117]. Isolates from Iran and Serbia showed predominantly substitutions of Asp87 with Asn and Gly/Asn, respectively, but no substitutions with Tyr [91,116]. Other substitutions at position 87 are rare and include one to Ser in an Egyptian isolate [39], which will be discussed in more detail below.

Ser83 of GyrA is mostly substituted with Phe in S. Enteritidis isolates with reduced or complete ciprofloxacin resistance, but substitution to Tyr has also been reported and has been implicated in reduced susceptibility to ciprofloxacin. A unique Ser83Ile substitution has been reported for a Malaysian isolate [108] (Table S2), and this mutation has recently been shown to confer a high level of quinolone resistance [118]. A novel mutation in GyrA, Ser97Pro, was found in an S. Enteritidis isolate from Brazil, but it does not seem to contribute to quinolone resistance [113] (Table S2). Double mutations in GyrA are not common in S. Enteritidis and have only been reported for a few isolates from Belgium [34], Brazil [112] and Thailand [115,119]. No mutations have been found in the GyrB subunit in any isolates analyzed to date. Four mutations in topoisomerase IV subunit ParC, Thr57Ser [32], Ser67Cys, Arg76Cys, Cys80Arg [39] (discussed later in detail) and one mutation in topoisomerase IV subunit ParE, Val521Phe [108] (Table S2) have been reported.

A clinical S. Enteritidis isolate was found to have a double mutation in GyrA, Ser83Phe and Asp87Ser (a rare substitution at this position), a novel triple mutation in ParC, Ser67Cys, Arg76Cys and Cys80Arg (Table S2), as well as an active efflux system, resulting in a very high MIC of ciprofloxacin of $256 \mathrm{mg} / \mathrm{L}$. Inhibition of the efflux system reduced the MIC of this isolate by a factor of 2, 3 or 4, depending on whether norepinephrine, carbonyl cyanide m-chlorophenylhydrazone or trimethoprim was used as an inhibitor [39]. It is worth mentioning that these inhibitors work in synergy with ciprofloxacin. This study by Rushdy et al. also shed light on the role of the altered expression of outer membrane 
porins in conferring high resistance to ciprofloxacin, but it did not explore the possible involvement of plasmid-mediated resistance. Overall, this study explained the role of some underrepresented quinolone-resistance mechanisms in greater depth. On the other hand, the novel mutations need further investigation, because the study based its analysis on an outdated nucleotide sequence that has been replaced with a sequence of $S$. Typhimurium str. LT2 (Genbank accession number AE006468). Our sequence alignment for ParC (Figure 6) shows that the wild-type residue for $S$. Typhimurium str. LT2 at position 67 and 76 are Val and Pro, respectively, rather than Ser and Arg as stated in the study. Similarly, as has been reported in many studies surveyed in this review, the wild-type residue at position 80 is not a Cys.

The importance of GyrA mutations at positions 83 and 87 in mediating ciprofloxacin resistance has been documented by many studies. It can also be speculated that the rare substitutions of residue at position 87 confer resistance because of its critical position in the enzyme. On the other hand, due to uncertainty regarding the nature of the wild-type residues, it is not possible to assess the capacity of the ParC mutations described above in conferring a resistance phenotype to Salmonella strains [39].

With respect to PMQR-determining elements in isolates with QRDR mutations, $S$. Enteritidis harbors the qnrS1 gene in isolates from Brazil, Malaysia, Belgium and Thailand, whereas the $q n r B$ and $a a c\left(6^{\prime}\right)-l b-c r$ genes have only been reported in isolates from Brazil (Table S2). Another study from China reported that PMQR determinants, i.e., the $q n r$ and $a a c\left(6^{\prime}\right)-I b-c r$ genes, are frequently detected in $S$. Enteritidis as well as in S. Derby, S. Agona and $S$. Typhimurium [103].

Some $S$. Enteritidis isolates also exhibit the non-classical phenotype, i.e., complete susceptibility to nalidixic acid and reduced susceptibility to ciprofloxacin with an MIC of ciprofloxacin in the range of $0.125-1 \mathrm{mg} / \mathrm{L}$ [107]. This phenotype in S. Enteritidis has been suggested to not be the result of the GyrB mutation observed for the typhoidal isolates described above, but instead to be due to the presence of PMQR determinants [107]. Concern has been raised about the widespread distribution of such non-classical Salmonella strains, because they are not detected in routine screenings in clinical settings that use the nalidixic acid resistance assay $[107,120]$ and because their unnoticed spread would compromise the use of ciprofloxacin for the treatment of salmonellosis.

\subsubsection{Salmonella Typhimurium (S. Typhimurium)}

S. Typhimurium is the leading cause of NTS infections [121]. S. Typhimurium-induced acute gastroenteritis is usually linked to the consumption of contaminated pig and bovine products $[104,107]$. S. Typhimurium phage type DT104 has been found to be multidrug resistant and is widely distributed, especially in Europe and North America [122,123].

The analysis of mutations in the QRDRs of $S$. Typhimurium isolates from around the world revealed the prevalence of a single mutation in GyrA either at position 83 or 87 (Table S3). Double mutants have been reported in isolates from China, and rare incidents reported from Belgium might be associated with travelers returning from China. Isolates carrying double mutations were also found to have an additional mutation in ParC, Ser80Arg. This ParC mutation was found in all double mutants except for one [34], which is also unusual in that it carries the Glu133Gly mutation in GyrA described above that is characteristic for typhoidal Salmonella (Table S3). Some isolates with a double mutation in GyrA were found to have the Ser80Ile substitution identified in Belgium [34]. Isolates with double mutations in GyrA and a single mutation in ParC also all have the Ser83Phe substitution in common [34,124,125]. In S. Typhimurium isolates, Asp87 is most commonly replaced by Asn (Table S3). In a study carried out on $S$. Typhimurium isolate from the US, the complete sequencing of gyrA gene instead of only QRDR region featured a single mutation in GyrA that results in the mutation of the proline (Pro) residue at position 864 to serine (Ser), and this mutation has been described to be likely associated with FQ resistance [27]. 
An $S$. Typhimurium isolate with exceptionally high resistance against ciprofloxacin, i.e., with an MIC of $512 \mathrm{mg} / \mathrm{L}$, has been identified in the Middle East and is characterized by a triple mutation in GyrA, Ser83Phe, Asp87Gly and Ala119Ser, and no mutation in ParC [39]. Mutations in GyrB would be a likely possibility for the high level of resistance, but GyrB was not examined for mutations in this study. However, the study found that this S. Typhimurium strain did not express OmpA, OmpC and OmpF and only little OmpD [39]. Efflux inhibition with carbonyl cyanide $\mathrm{m}$-chlorophenylhydrazone, trimethoprim, and norepinephrine resulted in reductions in the MIC by factors of 2, 3, and 4, respectively. Thus, while target alteration, downregulated influx and upregulated efflux all contribute to the high ciprofloxacin resistance of this isolate, it is possible that PMQR element (s) further contributed to the high resistance.

The GyrB and ParE subunits are rarely mutated in S. Typhimurium isolates. The only mutation in GyrB reported to date is a Glu466Asp substitution found in an isolate from Africa $[89,126]$. This mutation had previously been identified in typhoidal Salmonella isolates. Earlier studies associated another GyrB mutation, Ser464Phe, with high ciprofloxacin resistance, with MICs in the range of 16-32 $\mathrm{mg} / \mathrm{L}$ [127]. The only mutation identified in ParE to date, Met438Ile, was found in an isolate from Malaysia [108], but because this isolate also carries a PMQR gene, the extent by which the ParE mutation contributes to quinolone resistance is currently unclear.

An in vitro selection study of ciprofloxacin-resistant $S$. Typhimurium isolates showed that exposure of the parent $S$. Typhimurium strain (isolated from chicken, carrying a single mutation in ParC, Thr57Ser, and having an MIC of $0.03 \mathrm{mg} / \mathrm{L}$ ) to ciprofloxacin $(0.25 \mathrm{mg} / \mathrm{L})$ resulted in progeny that retained the Thr57Ser mutation in ParC but also acquired the Asn87Asp mutation in GyrA, increasing its MIC to $0.5 \mathrm{mg} / \mathrm{L}$. A subsequent increase in selection pressure by serially increasing the ciprofloxacin concentration from 2 to $4 \mathrm{mg} / \mathrm{L}$ resulted in progeny that only retained the GyrA and ParC mutations, but displayed an increased MIC of $8 \mathrm{mg} / \mathrm{L}$ [128], implying that the bacteria picked up another ciprofloxacin-resistance mechanism distinct from mutations in the target genes. A further increase in selection pressure by increasing the ciprofloxacin concentration to $64 \mathrm{mg} / \mathrm{L}$ resulted in progeny with an additional mutation in GyrB, Ser464Phe, while retaining the GyrA and ParC mutations. The MIC of this triple mutant was $32 \mathrm{mg} / \mathrm{L}$ [128]. This study concluded that efflux mediated by the AcrAB-TolC efflux pump played a crucial role in the increase in ciprofloxacin resistance before the acquisition of the GyrB mutation. Enhanced AcrAB-TolC expression was also found in an earlier in vitro selection study with the ciprofloxacin-resistant $S$. Typhimurium strain S21 (MIC $<0.15 \mathrm{mg} / \mathrm{L}$ ). Selection pressure due to ciprofloxacin concentrations ranging from 0.125 to $256 \mathrm{mg} / \mathrm{L}$ resulted in progeny that sequentially acquired first a mutation in GyrA, Ser83Phe, resulting in an MIC of $0.25 \mathrm{mg} / \mathrm{L}$, and then a second mutation in ParC, Ser80Ile, resulting in an MIC of $4 \mathrm{mg} / \mathrm{L}$ [129]. Even though a further increase in ciprofloxacin pressure resulted only in the retention of the GyrA and ParC mutations with no additional mutations being acquired, the MIC of the isolates increased to $32 \mathrm{mg} / \mathrm{L}$ and finally to $256 \mathrm{mg} / \mathrm{L}$. The increase in MIC without the acquisition of any additional mutations in the target genes was correlated with enhanced expression of the AcrAB-TolC efflux pump [129]. A different study on the generation of ciprofloxacin-resistant $S$. Typhimurium mutants implicated the RamA regulator in enhanced ciprofloxacin efflux [130].

Analysis of the above-mentioned in vitro-selected ciprofloxacin-resistant S. Typhimurium progenies and a survey of the isolates listed in Table S3 highlights the contribution of PMQR genes to quinolone resistance. Natural isolates demonstrate the $\mathrm{PMQR}$ determinants can enhance quinolone resistance to a level that mutations in GyrB or ParC are no longer required for survival. A clinical case reported by de Toro et al., on the in vivo selection of a quinolone-resistant $S$. Typhimurium isolate further illustrates this point. Treatment of an $S$. Typhimurium isolate, which was qnrS1 positive and displayed reduced susceptibility to ciprofloxacin (MIC of $0.5 \mathrm{mg} / \mathrm{L}$ ), with ciprofloxacin for 7 days resulted in a ciprofloxacin-resistant strain that retained the qnrS1 gene but also acquired 
the $a a c\left(6^{\prime}\right)$-Ib-cr gene and the Ser83Tyr mutation in GyrA, elevating its MIC to $8 \mathrm{mg} / \mathrm{L}$ [131]. This level of resistance is comparable to the resistance that can be attained by additional mutations in GyrA.

PMQR determinants identified in $S$. Typhimurium isolates with QRDR mutations include the $o q x A B, a a c\left(6^{\prime}\right)-I b-c r, q n r S 1$ and $q n r B$ genes. Under laboratory settings, the horizontal transfer of the $q n r S 1$ gene was found to increase the MIC of ciprofloxacin by a factor of 67 [131] and the combined horizontal transfer of the qnrS1 and aac $\left(6^{\prime}\right)$-Ib-cr genes resulted in an increase in the MIC by a factor of 133 [131]. S. Typhimurium strains without QRDR mutations but carrying PMQR genes have also been reported to harbor the qepA and $q n r S 1$ genes [106]. A non-classical S. Typhmurium strain with an MIC of ciprofloxacin of $4 \mathrm{mg} / \mathrm{L}$ was found to have no QRDR mutations and no PMQR genes [107], suggesting the involvement of a different resistance mechanism, such as increased efflux mediated by inner membrane transporters or reduced influx through outer membrane porins, and possibly even some as yet unknown mechanism. Efflux mediated by the AcrAB-TolC efflux pump seems to be a characteristic feature of ciprofloxacin-resistant $S$. Typhimurium isolates, as listed in Table S3 and supported by the in vitro-generated ciprofloxacin-resistant mutants. These studies reveal that an important mechanism by which $S$. Typhimurium acquires ciprofloxacin resistance is by activating efflux pumps mediated by the RamA regulator [130].

\subsubsection{Salmonella Hadar (S. Hadar)}

$S$. Hadar is another poultry-borne pathogen and is considered to be a reservoir of antibiotic resistance genes [132]. Our literature survey shows that $S$. serovar Hadar isolates with intermediate ciprofloxacin susceptibility from Europe and Asia mostly carry a mutation of Asp87 in GyrA (Table S4). S. Hadar isolates collected from Switzerland and Poland almost all showed this single Asp87 mutation, thus suggesting that this strain spread through clonal expansion $[28,133]$. Thong et al. came to a similar conclusion for food-borne $S$. Hadar isolates from different locations in Malaysia. Despite their diverse origins, all isolates shared the same QRDR mutations, namely Asp87Tyr in GyrA and Thr57Ser in ParC, indicative of the clonal spread of this strain [108]. While the Asp87Tyr mutation in GyrA is dominant in S. Hadar isolates from Malaysia [108] and Korea [134], the Asp87Asn is more common in isolates from Belgium, Poland, Morocco and Spain [34,135]. The Asp87Gly mutation, although frequent in other Salmonella serovars, has not yet been reported in S. Hadar. Substitutions of GyrA residue Ser83 with Tyr and Phe have been found in isolates from Belgium and Switzerland [34,133].

Among the $S$. Hadar isolates with partial or complete ciprofloxacin resistance, none showed mutations in GyrB. The ParC subunit in $S$. Hadar frequently carries the known Thr57Ser or Ser80Ile mutations (Table S4). Furthermore, an isolate from Malaysia featured a novel double mutation in ParC, namely Arg96Ser and Pro98Lys [108], but the role of these mutations in ciprofloxacin resistance remains to be defined.

An earlier study reported that the position of the mutation in GyrA correlates strongly with the place of origin of an $S$. Hadar strain, with mutations at position 83 usually being found in isolates from Southeast Asia and mutations at position 87 being found in isolates from Southern Europe and North Africa [136]. However, in vitro induction of mutations in $S$. Hadar demonstrated that exposure of this serovar to ciprofloxacin usually first resulted in the acquisition of a mutation at position 87 [137], indicating that the geographic distribution of certain mutations may be the result of the use of particular quinolones in these regions. Our literature survey supports this notion.

Plasmid-encoded resistance determinants found in $S$. Hadar isolates with QRDR mutations include the $q n r D$ gene $[34,133]$. An $S$. Hadar isolate collected in Switzerland was found to carry the novel qnrD2 variant (Table S4). This variant differs from $q n r D 1$ by two substitutions, Ile189Thr and Leu202Phe, but these have no effect on ciprofloxacin resistance [133]. Recently, an $S$. serovar Hadar isolate with an MIC of ciprofloxacin of $0.5 \mathrm{mg} / \mathrm{L}$ but having no QRDR mutations was found to carry the qnrB19 gene [138]. Efflux 
of ciprofloxacin in S. Hadar isolates was only investigated in one study, which found that it did contribute to reduced ciprofloxacin susceptibility [106].

\subsubsection{Salmonella Kentucky (S. Kentucky)}

$S$. Kentucky is one of the most frequently isolated serovars from poultry carcasses and the spread of the ciprofloxacin-resistant $S$. Kentucky ST198 isolate is posing a potential threat to farm animals (chicken, turkey and swine), wildlife and humans $[139,140]$. A research-based survey carried out in 28 countries [140] reported the international dissemination of the ST198 strain with isolates reported from the European Union [141] and North America [142,143].

The mutations in S. Kentucky isolate ST198 have already been comprehensively discussed by Le Hello et al. [140] and will therefore not be covered in this review. According to Le Hello et al., the particular substitution of GyrA residue Asp87 is characteristic for S. Kentucky ST198 isolates from different geographic regions, with North African and Southeast Asian isolates being characterized by Asp87Asn, Middle Eastern isolates by both Asp87Asn and Asp87Gly, East African and Indian isolates by Asp87Tyr, and West African isolates by Asp87Gly [140]. This literature survey found an S. Kentucky ST198 isolate from a patient in Switzerland carrying the Asp87Asn mutation. This patient likely contracted the pathogen during a trip to Libya, where this mutation is prevalent [144].

Our literature survey indicates the prevalence of ciprofloxacin-resistant $S$. Kentucky strains in Africa [30,41] Europe [28,34,133] and Asia [41,145] (Table S5). Many of these strains are either confirmed or suspected to be $S$. Kentucky ST198 [28,30,41,144]. Analysis of the QRDR mutations reveals that $S$. Kentucky is prone to altering its chromosomal DNA in response to exposure to ciprofloxacin. Characteristic of ciprofloxacin-resistant isolates of $S$. Kentucky is the combination of a single mutation in GyrA, typically Ser83Phe, or a double mutation, Ser83Phe and substitution of Asp87 to Tyr, Gly or Asn, with single or double mutations in the ParC subunit of topoisomerase IV (Table S5).

The contribution of ParC mutations to conferring ciprofloxacin resistance in $S$. Kentucky is debatable. A Thr57Ser mutation in ParC was identified in two ciprofloxacinsusceptible Salmonella control strains as well as in an S. Kentucky isolate susceptible to nalidixic acid in an earlier study [146], suggesting that this mutation is not involved in resistance [147] but rather represents an unimportant sequence variation [119]. The presence of double mutations in GyrA and ParC resulting in elevated resistance has been reported for an S. Kentucky ST198 epidemic clone [148]. In surveying $S$. Kentucky mutations, isolates from Belgium, all of them from humans, showed a double mutation in the par $C$ gene, Thr57Ser and Ser80Ile, together with PMQR elements, namely qnrB1 or qnrD. It should be noted that the clonal spread of the S. Kentucky ST198 genotype in Belgium was reflected in the PFGE-XbaI profiles of seven randomly chosen isolates, which showed $92 \%$ sequence identity [34]. Another notable feature of the $S$. Kentucky strain is that although mutation of Ser80 is common, it is always substituted by Ile and never by Arg (Table S5).

Ciprofloxacin efflux has not been studied in most of the $S$. Kentucky isolates. However, mutations in the regulatory ramR gene have been reported to enhance AcrAB expression in some S. Kentucky ST198 isolates, thus increasing ciprofloxacin efflux [41]. Studies investigating the effect of mutations in RamR found a two- to six-fold increase in AcrA expression, accounting for the elevated resistance in these isolates [41,146].

Our literature survey found that $S$. Kentucky ST198 isolates expressing PMQR genes have exceptionally high MIC for ciprofloxacin, namely 32 and $24 \mathrm{mg} / \mathrm{L}$ for isolates expressing $q n r B 1$ and $q n r D$, respectively (Table S5). It must be noted, however, that no PMQR genes were identified in an earlier study of S. Kentucky ST198 isolates [139].

\subsubsection{Salmonella Indiana (S. Indiana)}

$S$. Indiana is a highly pathogenic strain that infects both humans and birds and causes acute enteritis and diarrhea. S. Indiana isolates have been identified in China, mainly in individuals working in meat retail, slaughter houses and chicken farms [128]. 
Our survey of QRDR mutations and their co-existence with PMQR genes revealed an alarming situation for $S$. serovar Indiana $[149,150]$. Most isolates carry both a double mutation in GyrA as well as a single or double mutation in the ParC subunit of topoisomerase IV. Substitution of GyrA residue Ser83 by Phe is prevalent with substitutions by Ile, Leu and Tyr being less frequent. In contrast, Asp87 is equally often substituted by Asn or Gly, but has not yet been found to be substituted by Tyr (Table S6). Besides these most commonly mutated residues, analysis of QRDR mutations in $S$. Indiana isolates from China's Shandong Province [150] and Henan Province [151,152] revealed additional mutations. S. Indiana isolates collected in Henan Province showed a prevalence of the Ser80Arg substitution in ParC [151,152] while isolates from Shandong Province carried the Ser80Ile substitution (Table S6) [150]. S. Indiana isolates from Henan Province were found to have more transferable resistance elements. The Ser80Ile substitution and transferable resistance elements were also found in isolates collected from China's Guangdong Province [149].

An in vitro study found that exposure of a parent $S$. Indiana strain, isolated from pig with no QRDR mutations and an MIC of ciprofloxacin of $0.125 \mathrm{mg} / \mathrm{L}$, to ciprofloxacin at a concentration of $0.25 \mathrm{mg} / \mathrm{L}$ resulted in progeny with an MIC of $0.5 \mathrm{mg} / \mathrm{L}$ that acquired the Ser83Phe mutation in GyrA. An increase in the ciprofloxacin concentration to $1 \mathrm{mg} / \mathrm{L}$ resulted in progeny that retained the Ser83Phe mutation but displayed an increased MIC of $4 \mathrm{mg} / \mathrm{mL}$ [128]. A further increase in the ciprofloxacin concentration to $4 \mathrm{mg} / \mathrm{L}$ resulted in progeny with an MIC of $16 \mathrm{mg} / \mathrm{L}$ that acquired an additional GyrA mutation, Asp87Gly. Yet another increase in ciprofloxacin concentration to $8 \mathrm{mg} / \mathrm{L}$ resulted in progeny with an MIC of $32 \mathrm{mg} / \mathrm{L}$ that acquired an additional mutation in ParC, Thr57Ser [128]. In vivo S. Indiana isolates have not been investigated for efflux activity (Table S6), but in vitro-selected ciprofloxacin-resistant mutants showed an increase in ciprofloxacin accumulation when treated with efflux pump inhibitor, indicating the presence of an active efflux system [128]. The contribution of the novel mutations in conferring FQs resistance thus remains to be defined. The role of a putatively novel Cys72 Gly mutation in ParC [153] also remains unclear, because our sequence alignment indicates that Gly is actually the wild-type residue at this position in S. Typhimurium str. LT2 (Figure 6).

$S$. Indiana is the only serovar to date that was found to carry all the known PMQR determinants [154], except for $q n r C$. Among these PMQR determinants, the $a a c\left(6^{\prime}\right)-I b-c r$ gene is the most prevalent in $S$. Indiana, followed by the $\circ q x A B$, and the qepA, qnrA, qnrB, $q n r D$ and $q n r A$ genes, which are much less prevalent [154]. Given the universal occurrence of transferrable resistance determinants in $S$. Indiana, their dissemination through conjugation poses a serious threat. However, under laboratory conditions, conjugation was usually unsuccessful, with the exceptions of studies by Bai et al. and Jiang et al., whichfound transconjugants carrying the oqxA, oqxB and aac( $\left.6^{\prime}\right)-I b$-cr genes [151] and the $q n r A, a a c(6)-I b-c r$ and $o q x A$ genes, respectively [149].

\subsubsection{Salmonella Infantis (S. Infantis)}

S. Infantis is another poultry-related Salmonella serovar. Based on the analysis of isolates from Europe [28,34,155], Asia [114] and South America [32], S. Infantis isolates have a high prevalence of the Ser83Tyr mutation in GyrA together with the Thr57Ser mutation in ParC (Table S7). Exceptions include isolates from Iran, which were found to mostly carry a mutation of Asp87 to Tyr or Asn [91,156]. In an S. Infantis isolate from Iran, the novel Leu41Pro mutation was found to co-exist with the Asp87Tyr mutation [91] (Table S7). However, it is not yet clear whether this variation represents a sequence polymorphism or an actual ciprofloxacin-resistance determinant.

To date, only a single GyrB mutation has been found in S. Infantis, the novel Leu470Met substitution. Because this mutation co-exists with GyrA mutation Ser83Tyr and ParC mutation Thr57Ser, it remains to be determined whether it actually contributes to the reduced ciprofloxacin susceptibility of this isolate [28]. The only PMQR determinant reported to date for $S$. Infantis isolates with QRDR mutations is qnrA1 (Table S7). 


\subsubsection{Salmonella Derby (S. Derby)}

$S$. Derby is one of the most prevalent serovars in pigs and pork-related products in Europe, North America and Asia, ranking among the top 10 human-associated Salmonella serovars $[153,157]$. S. Derby isolates identified in Europe were found to be susceptible to ciprofloxacin [157-159].

In our literature survey, all isolates from Europe [34] and Asia [134,153] were found to have a single mutation in GyrA (Table S8). However, isolates from Europe and Asia differ in that isolates from Europe also carry a ParC mutation but no PMQR genes [34], whereas the opposite is true for isolates from Asia [134,153].

In a comprehensive study, Lin et al. found that pork samples collected from retail meat in China harbored $S$. Derby with very high ciprofloxacin resistance reflected in their MIC of $2 \mathrm{mg} / \mathrm{L}$ [153]. The isolates featured a novel GyrA mutation, Asn78His, but since they also expressed the acetyl transferase enzyme, the contribution of this new mutation to ciprofloxacin resistance remains to be determined. It is worth mentioning that our current survey finds that His is in fact the wild-type residue at position 78 in $S$. Typhimurium str. LT2 (Figure 3) and not Asn, as stated in this study [153]. Many S. Derby isolates having a single target gene mutation were found to carry three PMQR genes (Table S8) [153]. The presence of these genes in such a high number is alarming, but in a study of Chinese isolates, none of these ciprofloxacin-resistance determinants could be transferred to a recipient $E$. coli strain. Analysis of a representative $S$. Derby isolate revealed that the aac $\left(6^{\prime}\right)-I b-c r$, oq $x A B$ and qnrS2 genes were all integrated in the chromosomal DNA, rather than being carried on a plasmid, but the $a a c\left(6^{\prime}\right)-I b-c r$ gene was also detected on a plasmid [153]. The integration of the oq $x A B$ gene into the chromosomal DNA, which has already been reported in an earlier study, suggests clonal dissemination of oq $x A B$-positive $S$. Derby in the local food supply network of Hong Kong [160].

An S. Derby isolate with an MIC of ciprofloxacin of $2 \mathrm{mg} / \mathrm{L}$ but havng no QRDR mutations was found to carry four PMQR genes, namely aac (6 $\left.6^{\prime}\right)-I b-c r$, oq $x A B$, qnrS2 and $q n r B 8$, as well as to have the oq $x A B$ and qnrS2 genes integrated in its chromosome [153]. The efflux efficiency of chromosomally integrated oq $x A B$ genes is unclear, because the inhibition of the efflux system in this isolate and the one described above with Phe-Arg- $\beta$ naphthylamide did not result in a substantial decrease in the MIC, indicating the absence of an efficient efflux activity. However, the MIC of another isolate with no QRDR mutations and chromosomally integrated oqxAB, qnrS2 and $a a c\left(6^{\prime}\right)-\mathrm{Ib}-\mathrm{cr}$ dropped from $16 \mathrm{mg} / \mathrm{L}$ to $2 \mathrm{mg} / \mathrm{L}$ in the presence of an efflux pump inhibitor [153].

\subsubsection{Salmonella Newport (S. Newport)}

$S$. Newport has been isolated from human clinical samples, retail meat and seafood. Analysis of mutations in the QRDRs of $S$. Newport isolates from Europe [28,34], Asia [108,134] and South America [112] showed that double mutations are prevalent with one mutation in the GyrA subunit, either at position 83 or 87, and another mutation in the ParC subunit, usually Thr57Ser (Table S9). A Malaysian isolate had only a single mutation in GyrA but a novel double mutation in ParC, Arg96Ser and Pro98Thr [108].

A study from India reported that exposure of an originally susceptible $S$. Newport isolate to increasing concentrations of nalidixic acid resulted in mutant progeny with an MIC of $>256 \mathrm{mg} / \mathrm{L}$ carrying the Asp87Gly mutation and displaying active efflux activity [161]. Simultaneous screening of in vivo nalidixic acid-resistant $S$. Newport isolates found that isolates carrying the Asp87Asn mutation in GyrA have an MIC of nalidixic acid of $>256 \mathrm{mg} / \mathrm{L}$ [161]. This study thus showed a prevalence of the Asp87 mutation in nalidixic acid-resistant $S$. Newport isolates. However, a study by Wasyl et al. reported the prevalence of not only Asp87Gly in S. Newport isolates but also of the Ser83Tyr and Ser83Phe mutations (Table S9) and diverse PFGE-XbaI profiles, hinting at the contribution of several clones to the spread of $S$. Newport [28], a notion that is consistent with our literature survey. 
In terms of PMQR genes, qnrS1 and qnrS3 have been found in $S$. Newport isolates from Europe [28,34] and Asia [108]. Isolates from turkey meat in Denmark with MICs ranging from 0.5 to $1 \mathrm{mg} / \mathrm{L}$ carried a different PMQR determinant, qnrB5, as well as the Thr57Ser mutation in ParC [162]. S. Newport strains with a non-classical phenotype that escape routine susceptibility assays pose a serious threat [107]. Moreover, plasmid-borne ciprofloxacin resistance is more common in this serovar than chromosomally encoded resistance [163].

\subsubsection{Salmonella Virchow (S. Virchow)}

Salmonella serotype Virchow ranks among the five most abundant Salmonella serovars in Europe [164] and is mainly linked to imported poultry meat. A study from Portugal found a high level of quinolone resistance in S. Virchow isolates [165].

In a study of $S$. Virchow isolates collected in Switzerland, all of them carried the same Asp87Tyr substitution in GyrA, including isolates associated with travel to Thailand, suggesting a well-established $S$. Virchow genotype with quinolone resistance due to this target gene mutation [133]. However, a simultaneous report by Wasyl et al., studying quinolone-resistance mechanisms among Salmonella isolates from Poland, identified diverse GyrA mutations (Table S10) in three $S$. Virchow isolates with indistinguishable PFGE-XbaI profiles, including a double mutation in GyrA with intermediate ciprofloxacin susceptibility [28]. Overall, our literature survey establishes that there is no preferred site of mutation in GyrA associated with quinolone resistance in $S$. Virchow isolates, but among the most frequent mutations are the Ser83Phe and Asp87Tyr substitutions.

Mutations in GyrB, ParC and ParE have not been identified in any $S$. Virchow isolate from Europe [28,34,133], Africa [30] and Asia [119,134,166] (Table S10). One isolate from Thailand was found to have a Val95Leu mutation in ParC, but this mutation was also present in ciprofloxacin-susceptible isolates and was therefore excluded from playing a role in ciprofloxacin resistance [119]. Based on our sequence alignment study, the wild-type residue at position 95 in ParC is Tyr (Figure 6). PMQR genes identified in $S$. Virchow isolates include qnrS1 and qnrB2 genes $[133,166]$. Conjugational transfer of the PMQR genes was not successful for all $S$. Virchow isolates, except for one Swiss isolate bearing a plasmid with the qnrS1 gene. An $S$. Virchow isolate collected from retail pork in China carried four PMQR genes, aac- $\left(6^{\prime}\right)-I b-c r, o q x A B$, qnrS8 and $q n r D$. This isolate showed a high resistance to ciprofloxacin with an MIC of $4 \mathrm{mg} / \mathrm{L}$, even though it carried no QRDR mutations [153]. The mutations identified in type-II topoisomerases of NTS have been depicted in Figures 4-7 for GyrA, GyrB, ParC and ParE, respectively. The summary of these mutations is also given in Figure 8.

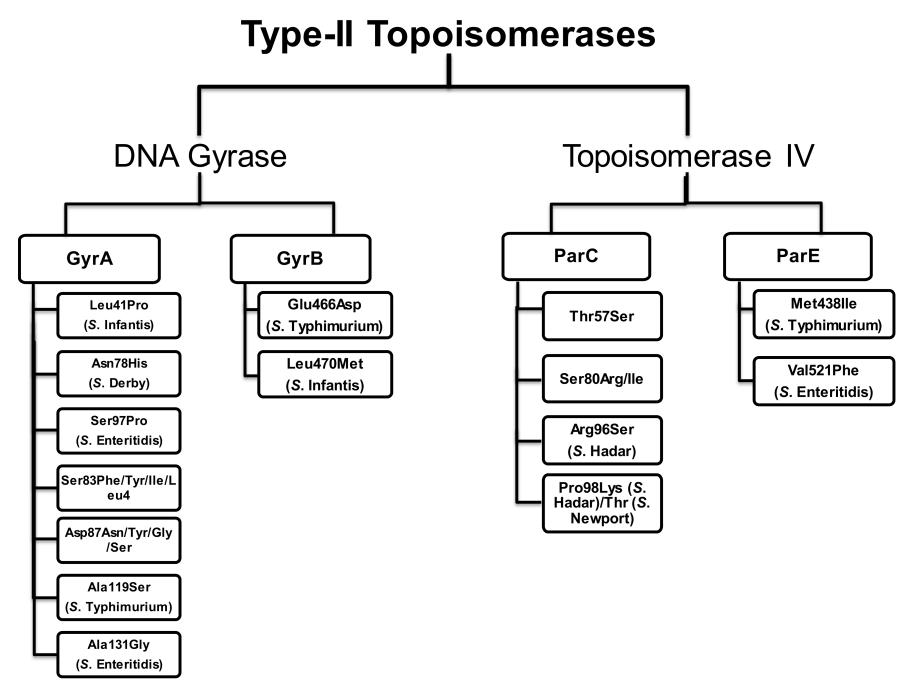

Figure 8. Mutations in the QRDRs of NTS. 


\section{Conclusions}

This literature review illustrates how Salmonella serovars evade the consistent evolutionary pressure associated with the use of FQs to treat typhoidal and non-typhoidal salmonellosis by acquiring mutations in their QRDRs, as well as PMQR determinants and/or efflux mechanisms. Typhoidal Salmonella, in particular S. Typhi and S. Paratyphi A, respond to antibiotics exposure predominantly by acquiring the Ser83Phe substitution in GyrA. While Ser83 mutations have previously been reported to account for more than $>90 \%$ of all QRDR mutations [16,167], the acquisition of the qnrS1 gene is another mechanism by which $S$. Typhi adapts to ciprofloxacin pressure. S. Enteritidis and S. Typhimurium are the most extensively studied non-typhoidal serovars. The Asp87Tyr substitution is most prevalent in ciprofloxacin-resistant $S$. Enteritidis isolates, but the Ser83Phe substitution is also common. S. Typhimurium isolates show even less prevalence for a specific GyrA mutation in response to ciprofloxacin exposure, with Ser83 and Asp87 mutations having very similar frequencies. Ciprofloxacin extrusion mediated by efflux transporters is another resistance mechanism that cannot be ruled out for Salmonella serovars Typhimurium and Enteritidis. Our literature review establishes $S$. Kentucky and $S$. Indiana as emerging threats to food imports, because increasing numbers of isolates are found to be ciprofloxacin resistant, and also emphasizes the critical importance of surveilling $S$. Typhimurium, $S$. Indiana and $S$. Derby to control the spread of transferable ciprofloxacin-resistance determinants.

Several issues require further attention. An important question is whether the complete resistance of many of the single-mutation Salmonella strains is indeed just due to the acquisition of the single QRDR mutations or is in fact also based on contributions by other resistance mechanisms, such as reduced porin expression or increased transportermediated efflux. While several new mutations have been identified in currently circulating typhoidal and non-typhoidal Salmonella strains, more studies are needed to understand their role in ciprofloxacin resistance. In this respect, our literature survey highlights the importance of careful analysis of the correct reference nucleotide sequence to identify novel mutations. The emergence of non-classical resistant Salmonella strains, characterized by high susceptibility to nalidixic acid and reduced or intermediary susceptibility to ciprofloxacin, is a major threat for the dissemination of drug-resistant Salmonella serovars. Because routine screening uses nalidixic acid to evaluate the drug resistance of Salmonella serovars, non-classical Salmonella strains are not detected, establishing the need for improved diagnostic procedures. The substantial role that transporter-mediated efflux plays in quinolone resistance poses a need for further investigations, particularly for natural isolates. The sparsity of data for Southeast Asia also calls for research-based surveys in this area, where Salmonella is endemic. Finally, the lack of studies focusing on less frequent serovars, such as $S$. Choleraesuis, $S$. Dublin, $S$. Heidelberg, $S$. Rissen, $S$. Schwarzengrund, $S$. Stanley, $S$. Tennessee and others, makes it impossible at this point to establish the presence of mutations potentially conferring antibiotic resistance and thus to assess the risk they pose to humanity.

In conclusion, this overview of QRDR mutations in Salmonella serovars provides a snapshot of currently circulating ciprofloxacin-resistant strains, but Salmonellae have also developed resistance to other antibiotics. Azithromycin is among the non-FQ antibiotics being used for the treatment of salmonellosis, particularly typhoidal salmonellosis. However, azithromycin has already been reported against and the molecular mechanism underlying this resistance phenotype has been identified as mutations in the inner membrane efflux protein AcrB [168] and its regulatory protein AcrR [169]. Antibiotics belonging to the cephalosporin family have also been used to treat typhoid fever. Again, resistance to these antibiotics has already emerged in Salmonella and in this case is mediated by plasmid-borne factors [170]. Typhoidal Salmonella are endemic in developing countries and food imports are the cause for the occurrence of non-typhoidal Salmonella in developed countries. A coordinated effort between developed and developing nations is of critical importance to curtail the further spread of Salmonella among communities worldwide. Moreover, there is urgent need to fight drug resistance to combat the emergence of extensively multi- and pan- 
drug-resistant Salmonella strains. Currently, different plant-based inhibitors and synthetic peptides are being investigated for their capacity to fight drug resistance [171,172].

Supplementary Materials: The following are available online at https:/ /www.mdpi.com/article/ 10.3390/antibiotics10121455/s1, Figure S1: Amino acid sequence alignment of the GyrA homologs, Figure S2: Amino acid sequence alignment of the GyrB homologs, Figure S3: Amino acid sequence alignment of the ParC homologs, Figure S4: Amino acid sequence alignment of the ParE homologs, Table S1: Mutations in QRDRs of typhoidal Salmonella, Table S2: Mutations in QRDRs of Salmonella Enteritidis, Table S3: Mutations in QRDRs of Salmonella Typhimurium, Table S4: Mutations in QRDRs of Salmonella Hadar, Table S5: Mutations in QRDRs of Salmonella Kentucky, Table S6: Mutations in QRDRs of Salmonella Indiana, Table S7: Mutations in QRDRs of Salmonella Infantis, Table S8: Mutations in QRDRs of Salmonella Derby, Table S9: Mutations in QRDRs of Salmonella Newport, Table S10: Mutations in QRDRs of Salmonella Virchow.

Author Contributions: Conceptualization, A.S. and M.R.; literature survey, A.S., A.T., M.I. and A.H.; writing-original draft preparation, A.S., A.H., O.M., T.W. and M.R.; writing-review and editing, A.S., O.M., T.W., M.R.; supervision, M.R.; funding acquisition, M.R. and A.S. All authors have read and agreed to the published version of the manuscript.

Funding: This work was supported by the Higher Education Commission of Pakistan (grant no. 20-1504) to M.R. and (SRGP grant no. 1197) to A.S.

Conflicts of Interest: The authors declare no conflict of interest.

\section{References}

1. Pham, T.D.M.; Ziora, Z.M.; Blaskovich, M.A.T. Quinolone antibiotics. MedChemComm 2019, 10, 1719-1739. [CrossRef]

2. Brighty, K.E.; Gootz, T.D. Chemistry and mechanism of action of the quinolone antibacterials. In The Quinolones, 3rd ed.; Academic Press: Cambridge, MA, USA, 2000.

3. Campoli-Richards, D.M.; Monk, J.P.; Price, A.; Benfield, P.; Todd, P.A.; Ward, A. Ciprofloxacin: A review of its antibacterial activity, pharmacokinetic properties and therapeutic use. Drugs 1988, 35, 373-447. [CrossRef]

4. Monk, J.P.; Campoli-Richards, D.M. Ofloxacin: A review of its antibacterial activity, pharmacokinetic properties and therapeutic use. Drugs 1987, 33, 346-391. [CrossRef] [PubMed]

5. Hamer, D.H.; Gorbach, S.L. Use of the quinolones for treatment and prophylaxis of bacterial gastrointestinal infections. In The Quinolones; Academic Press: Cambridge, MA, USA, 2000; p. 303.

6. Crump, J.A.; Sjolund-Karlsson, M.; Gordon, M.A.; Parry, C.M. Epidemiology, clinical presentation, laboratory diagnosis, antimicrobial resistance, and antimicrobial management of invasive Salmonella infections. Clin. Microbiol. Rev. 2015, 28, 901-937. [CrossRef] [PubMed]

7. Kariuki, S.; Gordon, M.A.; Feasey, N.; Parry, C.M. Antimicrobial resistance and management of invasive Salmonella disease. Vaccine 2015, 33, C21-C29. [CrossRef]

8. Gunn, J.S.; Marshall, J.M.; Baker, S.; Dongol, S. Salmonella chronic carriage: Epidemiology, diagnosis, and gallbladder persistence. Trends Microbiol. 2014, 22, 648-655. [CrossRef]

9. Lodish, H.B.A.; Berk, A.; Zipursky, S.L.; Matsudaira, P.; Baltimore, D.; Darnell, J. The role of topoisomerases in DNA replication. In Molecular Cell Biology; WH Freeman: New York, NY, USA, 2000.

10. Dax, S.L. Antibacterial Chemotherapeutic Agents; Springer Science \& Business Media: Berlin/Heidelberg, Germany, 2012.

11. Champoux, J.J. DNA topoisomerases: Structure, function, and mechanism. Annu. Rev. Biochem. 2001, 70, 369-413. [CrossRef]

12. Wang, S.C.; Shapiro, L. The topoisomerase IV ParC subunit colocalizes with the Caulobacter replisome and is required for polar localization of replication origins. Proc. Natl. Acad. Sci. USA 2004, 101, 9251-9256. [CrossRef] [PubMed]

13. Hooper, D.C.; Jacoby, G.A. Mechanisms of drug resistance: Quinolone resistance. Ann. N. Y. Acad. Sci. 2015, 1345, 12-31. [CrossRef]

14. Wang, J.C. DNA topoisomerases. Annu. Rev. Biochem. 1996, 65, 635-692. [CrossRef]

15. Hegde, S.S.; Vetting, M.W.; Roderick, S.L.; Mitchenall, L.A.; Maxwell, A.; Takiff, H.E.; Blanchard, J.S. A fluoroquinolone resistance protein from Mycobacterium tuberculosis that mimics DNA. Science 2005, 308, 1480-1483. [CrossRef]

16. Aldred, K.J.; Kerns, R.J.; Osheroff, N. Mechanism of quinolone action and resistance. Biochemistry 2014, 53, 1565-1574. [CrossRef]

17. Hopkins, K.L.; Davies, R.H.; Threlfall, E.J. Mechanisms of quinolone resistance in Escherichia coli and Salmonella: Recent developments. Int. J. Antimicrob. Agents 2005, 25, 358-373. [CrossRef] [PubMed]

18. Pan, X.S.; Fisher, L.M. DNA gyrase and topoisomerase IV are dual targets of clinafloxacin action in Streptococcus pneumoniae. Antimicrob. Agents Chemother. 1998, 42, 2810-2816. [CrossRef]

19. Park, H.S.; Jung, S.J.; Kwak, J.H.; Choi, D.R.; Choi, E.C. DNA gyrase and topoisomerase IV are dual targets of zabofloxacin in Streptococcus pneumoniae. Int. J. Antimicrob. Agents 2010, 36, 97-98. [CrossRef] 
20. Yoshida, H.; Bogaki, M.; Nakamura, M.; Nakamura, S. Quinolone resistance determining region in the DNA gyrase gyrA gene of Escherichia coli. Antimicrob. Agents Chemother. 1990, 34, 1271-1272. [CrossRef] [PubMed]

21. Yoshida, H.; Bogaki, M.; Nakamura, M.; Yamanaka, L.M. Quinolone resistance determining region in the DNA gyrase gyrB gene of Escherichia coli. Antimicrob. Agents Chemother. 1991, 35, 1647-1650. [CrossRef] [PubMed]

22. Govinden, U.; Mocktar, C.; Moodley, P.; Sturm, A.; Essack, S. Detection of mutations in the gyrA of clinical Salmonella spp. Afr. J. Biotechnol. 2009, 8, 3911-3914.

23. Procter, J.B.; Carstairs, G.M.; Soares, B.; Mourao, K. Alignment of Biological Sequences with Jalview. Methods Mol. Biol. 2021, 2231, 203-224. [PubMed]

24. Afzal, A.; Sarwar, Y.; Ali, A.; Maqbool, A.; Salman, M.; Habeeb, M.A.; Haque, A. Molecular evaluation of drug resistance in clinical isolates of Salmonella enterica serovar Typhi from Pakistan. J. Infect. Dev. Ctries 2013, 7, 929-940. [CrossRef] [PubMed]

25. Friedman, S.M.; Lu, T.; Drlica, K. Mutation in the DNA gyrase A gene of Escherichia coli that expands the quinolone resistance determining region. Antimicrob. Agents Chemother. 2001, 45, 2378-2380. [CrossRef]

26. Madurga, S.; Sanchez-Cespedes, J.; Belda, I.; Vila, J.; Giralt, E. Mechanism of binding of fluoroquinolones to the quinolone resistance-determining region of DNA gyrase: Towards an understanding of the molecular basis of quinolone resistance. ChemBioChem 2008, 9, 2081-2086. [CrossRef]

27. An, R.; Alshalchi, S.; Breimhurst, P.; Munoz-Aguayo, J.; Flores-Figueroa, C.; Vidovic, S. Strong influence of livestock environments on the emergence and dissemination of distinct multidrug-resistant phenotypes among the population of non-typhoidal Salmonella. PLoS ONE 2017, 12, e0179005. [CrossRef] [PubMed]

28. Wasyl, D.; Hoszowski, A.; Zajac, M. Prevalence and characterisation of quinolone resistance mechanisms in Salmonella spp. Vet. Microbiol. 2014, 171, 307-314. [CrossRef] [PubMed]

29. Wright, A.P.; Richardson, L.; Mahon, B.E.; Rothenberg, R.; Cole, D.J. The rise and decline in Salmonella enterica serovar Enteritidis outbreaks attributed to egg-containing foods in the United States, 1973-2009. Epidemiol. Infect. 2016, 144, 810-819. [CrossRef] [PubMed]

30. Eguale, T.; Birungi, J.; Asrat, D.; Njahira, M.N.; Njuguna, J.; Gebreyes, W.A.; Gunn, J.S.; Djikeng, A.; Engidawork, E. Genetic markers associated with resistance to beta-lactam and quinolone antimicrobials in non-typhoidal Salmonella isolates from humans and animals in central Ethiopia. Antimicrob. Resist. Infect. Control. 2017, 6, 13. [CrossRef]

31. Chen, Z.; Bai, J.; Zhang, X.; Wang, S.; Chen, K.; Lin, Q.; Xu, C.; Qu, X.; Zhang, H.; Liao, M.; et al. Highly prevalent multidrug resistance and QRDR mutations in Salmonella isolated from chicken, pork and duck meat in Southern China, 2018-2019. Int. J. Food Microbiol. 2021, 340, 109055. [CrossRef] [PubMed]

32. Casas, M.R.; Camargo, C.H.; Soares, F.B.; da Silveira, W.D.; Fernandes, S.A. Presence of plasmid mediated quinolone resistance determinants and mutations in gyrase and topoisomerase in Salmonella enterica isolates with resistance and reduced susceptibility to ciprofloxacin. Diagn. Microbiol. Infect. Dis. 2016, 85, 85-89. [CrossRef] [PubMed]

33. Cavaco, L.M.; Hasman, H.; Xia, S.; Aarestrup, F.M. qnrD, a novel gene conferring transferable quinolone resistance in Salmonella enterica serovar Kentucky and Bovismorbificans strains of human origin. Antimicrob. Agents Chemother. 2009, 53, 603-608. [CrossRef] [PubMed]

34. Ceyssens, P.J.; Mattheus, W.; Vanhoof, R.; Bertrand, S. Trends in serotype distribution and antimicrobial susceptibility in Salmonella enterica isolates from humans in Belgium, 2009 to 2013. Antimicrob. Agents Chemother. 2015, 59, 544-552. [CrossRef] [PubMed]

35. Gaind, R.; Paglietti, B.; Murgia, M.; Dawar, R.; Uzzau, S.; Cappuccinelli, P.; Deb, M.; Aggarwal, P.; Rubino, S. Molecular characterization of ciprofloxacin resistant Salmonella enterica serovar Typhi and Paratyphi A causing enteric fever in India. J. Antimicrob. Chemother. 2006, 58, 1139-1144. [CrossRef] [PubMed]

36. Dimitrov, T.; Dashti, A.A.; Albaksami, O.; Udo, E.E.; Jadaon, M.M.; Albert, M.J. Ciprofloxacin resistant Salmonella enterica serovar Typhi from Kuwait with novel mutations in gyrA and parC genes. J. Clin. Microbiol. 2009, 47, 208-211. [CrossRef] [PubMed]

37. Kogaluru Shivakumaraswamy, S.; Vijaya Kumar, D.; Moleyuru Nagarajappa, V.; Karunasagar, I.; Karunasagar, I. Multiple antimicrobial resistance and novel point mutation in fluoroquinolone-resistant Escherichia coli isolates from Mangalore, India. Microb. Drug Resist. 2017, 23, 994-1001.

38. Correia, S.; Hebraud, M.; Chafsey, I.; Chambon, C.; Viala, D.; Torres, C.; de Toro, M.; Capelo, J.L.; Poeta, P.; Igrejas, G. Impacts of experimentally induced and clinically acquired quinolone resistance on the membrane and intracellular subproteomes of Salmonella typhimurium DT104B. J. Proteomics 2016, 145, 46-59. [CrossRef]

39. Rushdy, A.A.; Mabrouk, M.I.; Abu-Sef, F.A.; Kheiralla, Z.H.; Mohamed Abdel-All, S.; Saleh, N.M. Contribution of different mechanisms to the resistance to fluoroquinolones in clinical isolates of Salmonella enterica. Braz. J. Infect. Dis. 2013, 17, $431-437$. [CrossRef]

40. Kim, K.Y.; Woo, G.J. Expression of acrB and $\operatorname{ram} A$ in fluoroquinolone resistant mutants from multi-drug resistant Salmonella enterica serovar Haardt. Lett. Appl. Microbiol. 2011, 52, 484-490. [CrossRef]

41. Baucheron, S.; Le Hello, S.; Doublet, B.; Giraud, E.; Weill, F.X.; Cloeckaert, A. ramR mutations affecting fluoroquinolone susceptibility in epidemic multidrug-resistant Salmonella enterica serovar Kentucky ST198. Front. Microbiol. 2013, 4, 213. [CrossRef]

42. Shaheen, A.; Tariq, A.; Shehzad, A.; Iqbal, M.; Mirza, O.; Maslov, D.A.; Rahman, M. Transcriptional regulation of drug resistance mechanisms in Salmonella: Where we stand and what we need to know. World J. Microbiol. Biotechnol. 2020, 36, 85. [CrossRef] 
43. Shaheen, A.; Ismat, F.; Iqbal, M.; Haque, A.; Ul-Haq, Z.; Mirza, O.; De Zorzi, R.; Walz, T.; Rahman, M. Characterization of the multidrug efflux transporter styMdtM from Salmonella enterica serovar Typhi. Proteins 2021, 89, 1193-1204. [CrossRef]

44. Martinez-Martinez, L.; Pascual, A.; Jacoby, G.A. Quinolone resistance from a transferable plasmid. Lancet 1998, 351, 797-799. [CrossRef]

45. Vetting, M.W.; Hegde, S.S.; Fajardo, J.E.; Fiser, A.; Roderick, S.L.; Takiff, H.E.; Blanchard, J.S. Pentapeptide repeat proteins. Biochemistry 2006, 45, 1-10. [CrossRef] [PubMed]

46. Shah, S.; Heddle, J.G. Squaring up to DNA: Pentapeptide repeat proteins and DNA mimicry. Appl. Microbiol. Biotechnol. 2014, 98, 9545-9560. [CrossRef]

47. Xiong, X.; Bromley, E.H.; Oelschlaeger, P.; Woolfson, D.N.; Spencer, J. Structural insights into quinolone antibiotic resistance mediated by pentapeptide repeat proteins: Conserved surface loops direct the activity of a Qnr protein from a gram-negative bacterium. Nucleic Acids Res. 2011, 39, 3917-3927. [CrossRef]

48. Jacoby, G.A.; Walsh, K.; Mills, D.; Moreno, F. (Eds.) A new plasmid mediated gene for quinolone resistance. In Proceedings of the Forty-Fourth Interscience Conference on Antimicrobial Agents and Chemotherapy, Washington, DC, USA, 30 October-2 November 2004.

49. Wang, M.; Guo, Q.; Xu, X.; Wang, X.; Ye, X.; Wu, S.; Hooper, D.C.; Wang, M. New plasmid mediated quinolone resistance gene, $q n r C$, found in a clinical isolate of Proteus mirabilis. Antimicrob. Agents Chemother. 2009, 53, 1892-1897. [CrossRef] [PubMed]

50. Hata, M.; Suzuki, M.; Matsumoto, M.; Takahashi, M.; Sato, K.; Ibe, S.; Sakae, K. Cloning of a novel gene for quinolone resistance from a transferable plasmid in Shigella flexneri 2b. Antimicrob. Agents Chemother. 2005, 49, 801-803. [CrossRef]

51. Pons, M.J.; Gomes, C.; Ruiz, J. QnrVC, a new transferable Qnr-like family. Enferm. Infecc. Microbiol. Clin. 2013, 31, 191-192. [CrossRef] [PubMed]

52. Robicsek, A.; Strahilevitz, J.; Jacoby, G.A.; Macielag, M.; Abbanat, D.; Park, C.H.; Bush, K.; Hooper, D.C. Fluoroquinolone modifying enzyme: A new adaptation of a common aminoglycoside acetyltransferase. Nat. Med. 2006, 12, 83-88. [CrossRef] [PubMed]

53. Hansen, L.H.; Johannesen, E.; Burmolle, M.; Sorensen, A.H.; Sorensen, S.J. Plasmid encoded multidrug efflux pump conferring resistance to olaquindox in Escherichia coli. Antimicrob. Agents Chemother. 2004, 48, 3332-3337. [CrossRef]

54. Yamane, K.; Wachino, J.; Suzuki, S.; Arakawa, Y. Plasmid mediated qepA gene among Escherichia coli clinical isolates from Japan. Antimicrob. Agents Chemother. 2008, 52, 1564-1566. [CrossRef] [PubMed]

55. Yamane, K.; Wachino, J.; Suzuki, S.; Kimura, K.; Shibata, N.; Kato, H.; Shibayama, K.; Konda, T.; Arakawa, Y. New plasmid mediated fluoroquinolone efflux pump, QepA, found in an Escherichia coli clinical isolate. Antimicrob. Agents Chemother. 2007, 51, 3354-3360. [CrossRef]

56. Cattoir, V.; Poirel, L.; Nordmann, P. Plasmid-mediated quinolone resistance pump QepA2 in an Escherichia coli isolate from France. Antimicrob. Agents Chemother. 2008, 52, 3801-3804. [CrossRef] [PubMed]

57. Wang, D.; Huang, X.; Chen, J.; Mou, Y.; Li, H.; Yang, L. Characterization of genetic structures of the QepA3 gene in clinical isolates of Enterobacteriaceae. Front. Microbiol. 2015, 6, 1147. [CrossRef] [PubMed]

58. Wayne, P.A. Performance Standards for Antimicrobial Susceptibility Testing; Twenty-third informational supplement; Clinical and Laboratory Standards Institute: Annapolis Junction, MD, USA, 2010.

59. Hirai, K.; Aoyama, H.; Suzue, S.; Irikura, T.; Iyobe, S.; Mitsuhashi, S. Isolation and characterization of norfloxacin-resistant mutants of Escherichia coli K-12. Antimicrob. Agents Chemother. 1986, 30, 248-253. [CrossRef]

60. Piddock, L.J. Clinically relevant chromosomally encoded multidrug resistance efflux pumps in bacteria. Clin. Microbiol. Rev. 2006, 19, 382-402. [CrossRef] [PubMed]

61. Shaheen, A.; Ismat, F.; Iqbal, M.; Haque, A.; De Zorzi, R.; Mirza, O.; Walz, T.; Rahman, M. Characterization of putative multidrug resistance transporters of the major facilitator-superfamily expressed in Salmonella typhi. J. Infect. Chemother. 2015, 21, 357-362. [CrossRef]

62. Komp Lindgren, P.; Marcusson, L.L.; Sandvang, D.; Frimodt-Moller, N.; Hughes, D. Biological cost of single and multiple norfloxacin resistance mutations in Escherichia coli implicated in urinary tract infections. Antimicrob. Agents Chemother. 2005, 49, 2343-2351. [CrossRef]

63. Piddock, L.J. Mechanisms of fluoroquinolone resistance: An update 1994-1998. Drugs 1999, 58, 11-18. [CrossRef]

64. Tack, B.; Phoba, M.F.; Van Puyvelde, S.; Kalonji, L.M.; Hardy, L.; Barbe, B.; Van der Sande, M.A.B.; Monsieurs, E.; Deborggraeve, S.; Lunguya, O.; et al. Salmonella Typhi from blood cultures in the Democratic Republic of the Congo: A 10-year surveillance. Clin. Infect. Dis. 2019, 68, S130-S137. [CrossRef]

65. Perichon, B.; Courvalin, P.; Galimand, M. Transferable resistance to aminoglycosides by methylation of G1405 in $16 \mathrm{~S}$ rRNA and to hydrophilic fluoroquinolones by QepA-mediated efflux in Escherichia coli. Antimicrob. Agents Chemother. 2007, 51, $2464-2469$. [CrossRef]

66. Strahilevitz, J.; Jacoby, G.A.; Hooper, D.C.; Robicsek, A. Plasmid mediated quinolone resistance: A multifaceted threat. Clin. Microbiol. Rev. 2009, 22, 664-689. [CrossRef]

67. Bugarel, M.; Tudor, A.; Loneragan, G.H.; Nightingale, K.K. Molecular detection assay of five Salmonella serotypes of public interest: Typhimurium, Enteritidis, Newport, Heidelberg, and Hadar. J. Microbiol. Methods. 2017, 134, 14-20. [CrossRef] [PubMed]

68. Singh, V. Salmonella serovars and their host specificity. J. Vet. Sci. Anim. Husb. 2013, 1, 301. [CrossRef] 
69. Gay, K.; Robicsek, A.; Strahilevitz, J.; Park, C.H.; Jacoby, G.; Barrett, T.J.; Medalla, F.; Chiller, T.M.; Hooper, D.C. Plasmid mediated quinolone resistance in non-Typhi serotypes of Salmonella enterica. Clin. Infect. Dis. 2006, 43, 297-304. [CrossRef]

70. Siddiqui, T.R.; Bibi, S.; Mustufa, M.A.; Ayaz, S.M.; Khan, A. High prevalence of typhoidal Salmonella enterica serovars excreting food handlers in Karachi-Pakistan: A probable factor for regional typhoid endemicity. J. Health Popul. Nutr. 2015, 33, 27. [CrossRef] [PubMed]

71. Kuijpers, L.M.; Le Hello, S.; Fawal, N.; Fabre, L.; Tourdjman, M.; Dufour, M.; Sar, D.; Kham, C.; Phe, T.; Vlieghe, E.; et al. Genomic analysis of Salmonella enterica serotype Paratyphi A during an outbreak in Cambodia, 2013-2015. Microb. Genom. 2016, 2, e000092. [CrossRef]

72. Accou-Demartin, M.; Gaborieau, V.; Song, Y.; Roumagnac, P.; Marchou, B.; Achtman, M.; Weill, F.X. Salmonella enterica serotype Typhi with nonclassical quinolone resistance phenotype. Emerg. Infect. Dis. 2011, 17, 1091-1094. [CrossRef]

73. Commons, R.J.; McBryde, E.; Valcanis, M.; Powling, J.; Street, A.; Hogg, G. Twenty six years of enteric fever in Australia: An epidemiological analysis of antibiotic resistance. Med. J. Aust. 2012, 196, 332-336. [CrossRef] [PubMed]

74. Acharya, D.; Trakulsomboon, S.; Madhup, S.K.; Korbsrisate, S. Antibiotic susceptibility pattern and the indicator of decreased ciprofloxacin susceptibility of Salmonella enterica serovar Typhi isolated from Dhulikhel Hospital, Nepal. Jpn J. Infect. Dis. 2012, 65, 264-267. [CrossRef]

75. Yan, M.; Li, X.; Liao, Q.; Li, F.; Zhang, J.; Kan, B. The emergence and outbreak of multidrug-resistant typhoid fever in China. Emerg. Microbes Infect. 2016, 5, e62. [CrossRef]

76. Garcia-Fernandez, A.; Gallina, S.; Owczarek, S.; Dionisi, A.M.; Benedetti, I.; Decastelli, L.; Luzzi, I. Emergence of ciprofloxacin resistant Salmonella enterica serovar Typhi in Italy. PLoS ONE 2015, 10, e0132065.

77. Chau, T.T.; Campbell, J.I.; Galindo, C.M.; Van Minh Hoang, N.; Diep, T.S.; Nga, T.T.; Van Vinh Chau, N.; Tuan, P.Q.; Page, A.L.; Ochiai, R.L.; et al. Antimicrobial drug resistance of Salmonella enterica serovar typhi in asia and molecular mechanism of reduced susceptibility to the fluoroquinolones. Antimicrob. Agents Chemother. 2007, 51, 4315-4323. [CrossRef]

78. Veeraraghavan, B.; Anandan, S.; Muthuirulandi Sethuvel, D.P.; Puratchiveeran, N.; Walia, K.; Devanga Ragupathi, N.K. Molecular characterization of intermediate susceptible typhoidal Salmonella to ciprofloxacin, and its impact. Mol. Diagn. Ther. 2016, 20, 213-219. [CrossRef] [PubMed]

79. Pfeifer, Y.; Matten, J.; Rabsch, W. Salmonella enterica serovar Typhi with CTX-M beta-lactamase, Germany. Emerg. Infect. Dis. 2009, 15, 1533-1535. [CrossRef]

80. Lee, C.J.; Su, L.H.; Huang, Y.C.; Chiu, C.H. First isolation of ciprofloxacin resistant Salmonella enterica serovar Typhi in Taiwan. J. Microbiol. Immunol. Infect. 2013, 46, 469-473. [CrossRef] [PubMed]

81. Nair, S.; Unnikrishnan, M.; Turner, K.; Parija, S.C.; Churcher, C.; Wain, J.; Harish, N. Molecular analysis of fluoroquinoloneresistant Salmonella Paratyphi A isolate, India. Emerg. Infect. Dis. 2006, 12, 489-491. [CrossRef] [PubMed]

82. Keddy, K.H.; Smith, A.M.; Sooka, A.; Ismail, H.; Oliver, S. Fluoroquinolone-resistant typhoid, South Africa. Emerg. Infect. Dis. 2010, 16, 879-880. [CrossRef] [PubMed]

83. Pham Thanh, D.; Tran Vu Thieu, N.; Tran Thuy, C.; Loden, M.; Tuin, K.; Campbell, J.I.; Van Minh Hoang, N.; Voong Vinh, P.; Farrar, J.J.; Holt, K.E.; et al. Identification of Salmonella enterica serovar Typhi genotypes by use of rapid multiplex ligation dependent probe amplification. J. Clin. Microbiol. 2013, 51, 2950-2958. [CrossRef]

84. Kariuki, S.; Revathi, G.; Kiiru, J.; Mengo, D.M.; Mwituria, J.; Muyodi, J.; Munyalo, A.; Teo, Y.Y.; Holt, K.E.; Kingsley, R.A. Typhoid in Kenya is associated with a dominant multidrug-resistant Salmonella enterica serovar Typhi haplotype that is also widespread in Southeast Asia. J. Clin. Microbiol. 2010, 48, 2171-2176. [CrossRef]

85. Chiou, C.S.; Lauderdale, T.L.; Phung, D.C.; Watanabe, H.; Kuo, J.C.; Wang, P.J.; Liu, Y.Y.; Liang, S.Y.; Chen, P.C. Antimicrobial resistance in Salmonella enterica serovar Typhi isolates from Bangladesh, Indonesia, Taiwan, and Vietnam. Antimicrob. Agents Chemother. 2014, 58, 6501-6507. [CrossRef] [PubMed]

86. Koirala, K.D.; Thanh, D.P.; Thapa, S.D.; Arjyal, A.; Karkey, A.; Dongol, S.; Shrestha, U.M.; Farrar, J.J.; Basnyat, B.; Baker, S. Highly resistant Salmonella enterica serovar Typhi with a novel gyrA mutation raises questions about the long-term efficacy of older fluoroquinolones for treating typhoid fever. Antimicrob. Agents Chemother. 2012, 56, 2761-2762. [CrossRef] [PubMed]

87. Menezes, G.A.; Harish, B.N.; Khan, M.A.; Goessens, W.H.; Hays, J.P. Antimicrobial resistance trends in blood culture positive Salmonella Typhi isolates from Pondicherry, India, 2005-2009. Clin. Microbiol. Infect. 2012, 18, 239-245. [CrossRef] [PubMed]

88. Walther-Rasmussen, J.; Hoiby, N. Salmonella enterica serovar Typhi and S. Paratyphi A: Need to expand the QRDR region? Epidemiol. Infect. 2011, 139, 1281-1283. [CrossRef] [PubMed]

89. Eibach, D.; Al-Emran, H.M.; Dekker, D.M.; Krumkamp, R.; Adu-Sarkodie, Y.; Cruz Espinoza, L.M.; Ehmen, C.; Boahen, K.; Heisig, P.; Im, J.; et al. The emergence of reduced ciprofloxacin susceptibility in Salmonella enterica causing bloodstream infections in rural Ghana. Clin. Infect. Dis. 2016, 62, S32-S36. [CrossRef] [PubMed]

90. Vlieghe, E.R.; Phe, T.; De Smet, B.; Veng, C.H.; Kham, C.; Bertrand, S.; Vanhoof, R.; Lynen, L.; Peetermans, W.E.; Jacobs, J.A. Azithromycin and ciprofloxacin resistance in Salmonella bloodstream infections in Cambodian adults. PLoS Negl. Trop. Dis. 2012, 6, e1933. [CrossRef] [PubMed]

91. Hamidian, M.; Tajbakhsh, M.; Tohidpour, A.; Rahbar, M.; Zali, M.R.; Walther-Rasmussen, J. Detection of novel gyrA mutations in nalidixic acid-resistant isolates of Salmonella enterica from patients with diarrhoea. Int. J. Antimicrob. Agents 2011, 37, 360-364. [CrossRef] 
92. Renuka, K.; Kapil, A.; Kabra, S.K.; Wig, N.; Das, B.K.; Prasad, V.V.; Chaudhry, R.; Seth, P. Reduced susceptibility to ciprofloxacin and gyrA gene mutation in North Indian strains of Salmonella enterica serotype Typhi and serotype Paratyphi A. Microb. Drug Resist. 2004, 10, 146-153. [CrossRef]

93. Gupta, R.; Gaind, R.; Wain, J.; Deb, M.; Singh, L.C.; Basir, S.F. Characterization of non-classical quinolone resistance in Salmonella enterica serovar Typhi: Report of a novel mutation in gyrB gene and diagnostic challenges. Biomol. Detect. Quantif. 2014, 2, 30-34. [CrossRef]

94. Eaves, D.J.; Randall, L.; Gray, D.T.; Buckley, A.; Woodward, M.J.; White, A.P.; Piddock, L.J. Prevalence of mutations within the quinolone resistance determining region of $g y r A, g y r B$, parC, and parE and association with antibiotic resistance in quinoloneresistant Salmonella enterica. Antimicrob. Agents Chemother. 2004, 48, 4012-4015. [CrossRef]

95. Qian, H.; Cheng, S.; Liu, G.; Tan, Z.; Dong, C.; Bao, J.; Hong, J.; Jin, D.; Bao, C.; Gu, B. Discovery of seven novel mutations of gyrB, parC and parE in Salmonella Typhi and Paratyphi strains from Jiangsu Province of China. Sci. Rep. 2020, 10, 7359. [CrossRef] [PubMed]

96. Gopal, M.; Elumalai, S.; Arumugam, S.; Durairajpandian, V.; Kannan, M.A.; Selvam, E.; Seetharaman, S. GyrA ser83 and ParC trp106 mutations in Salmonella enterica serovar Typhi isolated from typhoid fever patients in tertiary care hospital. J. Clin. Diagn. Res. 2016, 10, DC14-DC18. [CrossRef] [PubMed]

97. Yan, M.; Yang, B.; Wang, Z.; Wang, S.; Zhang, X.; Zhou, Y.; Pang, B.; Diao, B.; Yang, R.; Wu, S.; et al. A large-scale community based outbreak of paratyphoid fever caused by hospital derived transmission in Southern China. PLoS Negl. Trop. Dis. 2015, 9, e0003859. [CrossRef] [PubMed]

98. Saitoh, T.; Morita, M.; Shimada, T.; Izumiya, H.; Kanayama, A.; Oishi, K.; Ohnishi, M.; Sunagawa, T. Increase in paratyphoid fever cases in Japanese travellers returning from Cambodia in 2013. Epidemiol. Infect. 2016, 144, 602-606. [CrossRef]

99. Al-Emran, H.M.; Eibach, D.; Krumkamp, R.; Ali, M.; Baker, S.; Biggs, H.M.; Bjerregaard-Andersen, M.; Breiman, R.F.; Clemens, J.D.; Crump, J.A.; et al. A multicountry molecular analysis of Salmonella enterica serovar Typhi with reduced susceptibility to ciprofloxacin in Sub-Saharan Africa. Clin. Infect. Dis. 2016, 62, S42-S46. [CrossRef] [PubMed]

100. Hassing, R.J.; Menezes, G.A.; van Pelt, W.; Petit, P.L.; van Genderen, P.J.; Goessens, W.H. Analysis of mechanisms involved in reduced susceptibility to ciprofloxacin in Salmonella enterica serotypes Typhi and Paratyphi A isolates from travellers to Southeast Asia. Int. J. Antimicrob. Agents 2011, 37, 240-243. [CrossRef] [PubMed]

101. Adachi, T.; Sagara, H.; Hirose, K.; Watanabe, H. Fluoroquinolone resistant Salmonella Paratyphi A. Emerg. Infect. Dis. 2005, 11, 172-174. [CrossRef] [PubMed]

102. Sjolund-Karlsson, M.; Howie, R.; Rickert, R.; Newton, A.; Gonzalez-Aviles, G.; Crump, J.A. Plasmid mediated quinolone resistance in isolates of Salmonella enterica serotype Typhi, USA. Int. J. Antimicrob. Agents 2015, 45, 88-90. [CrossRef]

103. Yang, B.; Qiao, L.; Zhang, X.; Cui, Y.; Xia, X.; Cui, S.; Wang, X.; Meng, X.; Ge, W.; Shi, X. Serotyping, antimicrobial susceptibility, pulse field gel electrophoresis analysis of Salmonella isolates from retail foods in Henan Province, China. Food Cont. 2013, 32, 228-235. [CrossRef]

104. European Centre for Disease Prevention and Control. The European Union summary report on antimicrobial resistance in zoonotic and indicator bacteria from humans, animals and food in 2015. EFSA J. 2019, 17, e05598. [CrossRef]

105. EFSA Panel on Biological Hazards. Scientific opinion on the public health risks of table eggs due to deterioration and development of pathogens. EFSA J. 2014, 12, 3782. [CrossRef]

106. Lunn, A.D.; Fàbrega, A.; Sánchez-Céspedes, J.; Vila, J. Prevalence of mechanisms decreasing quinolone-susceptibility among Salmonella spp. clinical isolates. Int. Microbiol. 2010, 13, 15-20. [PubMed]

107. Campos, M.J.; Palomo, G.; Hormeno, L.; Herrera-Leon, S.; Dominguez, L.; Vadillo, S.; Piriz, S.; Quesada, A. Prevalence of quinolone resistance determinants in non-typhoidal Salmonella isolates from human origin in Extremadura, Spain. Diagn. Microbiol. Infect. Dis. 2014, 79, 64-69. [CrossRef] [PubMed]

108. Thong, K.L.; Ngoi, S.T.; Chai, L.C.; Teh, C.S.J. Quinolone resistance mechanisms among Salmonella enterica in Malaysia. Microbial. Drug Resist. 2016, 22, 259-272. [CrossRef] [PubMed]

109. Karunakaran, R.; Tay, S.T.; Rahim, F.F.; Lim, B.B.; Puthucheary, S.D. Molecular analysis of ciprofloxacin resistance among non-typhoidal Salmonella with reduced susceptibility to ciprofloxacin isolated from patients at a tertiary care hospital in Kuala Lumpur, Malaysia. Jap. J. Infect. Dis. 2014, 67, 157-162. [CrossRef] [PubMed]

110. Kim, K.Y.; Park, J.H.; Kwak, H.S.; Woo, G.J. Characterization of the quinolone resistance mechanism in foodborne Salmonella isolates with high nalidixic acid resistance. Int. J. Food Microbiol. 2011, 146, 52-56. [CrossRef] [PubMed]

111. Bae, D.H.; Baek, H.J.; Jeong, S.J.; Lee, Y.J. Amino acid substitutions in gyrA and parC associated with quinolone resistance in nalidixic acid-resistant Salmonella isolates. Ir. Vet. J. 2013, 66, 23. [CrossRef] [PubMed]

112. Ferrari, R.; Galiana, A.; Cremades, R.; Rodriguez, J.C.; Magnani, M.; Tognim, M.C.; Oliveira, T.C.; Royo, G. Plasmid mediated quinolone resistance (PMQR) and mutations in the topoisomerase genes of Salmonella enterica strains from Brazil. Braz. J. Microbiol. 2013, 44, 651-656. [CrossRef]

113. Campioni, F.; Souza, R.A.; Martins, V.V.; Stehling, E.G.; Bergamini, A.M.M.; Falcao, J.P. Prevalence of gyrA mutations in nalidixic acid-resistant strains of Salmonella Enteritidis isolated from humans, food, chickens, and the farm environment in Brazil. Microb. Drug Resist. 2017, 23, 421-428. [CrossRef] [PubMed] 
114. Osawa, K.; Shigemura, K.; Shimizu, R.; Kato, A.; Kimura, M.; Katayama, Y.; Okuya, Y.; Yutaka, S.; Nishimoto, A.; Kishi, A.; et al. Antimicrobial resistance in Salmonella strains clinically isolated in Hyogo, Japan (2009-2012). Jpn. J. Infect. Dis. 2014, 67, 54-57. [CrossRef]

115. Utrarachkij, F.; Nakajima, C.; Changkwanyeun, R.; Siripanichgon, K.; Kongsoi, S.; Pornruangwong, S.; Changkaew, K.; Tsunoda, R.; Tamura, Y.; Suthienkul, O.; et al. Quinolone resistance determinants of clinical Salmonella Enteritidis in Thailand. Microb. Drug Resist. 2017, 23, 885-894. [CrossRef] [PubMed]

116. Kozoderovic, G.; Velhner, M.; Jelesic, Z.; Golic, N.; Lozo, J.; Kehrenberg, C. Prevalence of quinolone resistance and mutations in the topoisomerase genes in Salmonella enterica serotype Enteritidis isolates from Serbia. Int. J. Antimicrob. Agents 2012, 40, 455-457. [CrossRef] [PubMed]

117. Lee, S.; Park, N.; Yun, S.; Hur, E.; Song, J.; Lee, H.; Kim, Y.; Ryu, S. Presence of plasmid-mediated quinolone resistance (PMQR) genes in non-typhoidal Salmonella strains with reduced susceptibility to fluoroquinolones isolated from human salmonellosis in Gyeonggi-do, South Korea from 2016 to 2019. Gut Pathog. 2021, 13, 35. [CrossRef] [PubMed]

118. Koide, K.; San, L.L.; Pachanon, R.; Park, J.H.; Ouchi, Y.; Kongsoi, S.; Utrarachkij, F.; Nakajima, C.; Suzuki, Y. Amino acid substitution Ser83Ile in GyrA of DNA gyrases confers high-level quinolone resistance to nontyphoidal Salmonella without loss of supercoiling activity. Microb. Drug Resist. 2021, 27, 1397-1404. [CrossRef] [PubMed]

119. Sinwat, N.; Angkittitrakul, S.; Chuanchuen, R. Characterization of antimicrobial resistance in Salmonella enterica isolated from pork, chicken meat, and humans in Northeastern Thailand. Foodborne Pathog. Dis. 2015, 12, 759-765. [CrossRef] [PubMed]

120. Escribano, I.; Rodriguez, J.C.; Royo, G. Mutations in the gyrA gene in Salmonella enterica clinical isolates with decreased ciprofloxacin susceptibility. Int. J. Antimicrob. Agents 2004, 24, 300-303. [CrossRef] [PubMed]

121. Threlfall, E.; Wain, J.; Peters, T.; Lane, C.; De Pinna, E.; Little, C.; Wales, A.; Davies, R. Egg-borne infections of humans with Salmonella: Not only an S. Enteritidis problem. Worlds Poult. Sci. J. 2014, 70, 15-26. [CrossRef]

122. Helms, M.; Ethelberg, S.; Molbak, K.; Group, D.T.S. International Salmonella Typhimurium DT104 infections, 1992-2001. Emerg. Infect. Dis. 2005, 11, 859-867. [CrossRef] [PubMed]

123. Threlfall, E.J.; Rowe, B.; Ward, L.R. A comparison of multiple drug resistance in salmonellas from humans and food animals in England and Wales, 1981 and 1990. Epidemiol. Infect. 1993, 111, 189-197. [CrossRef] [PubMed]

124. Wang, J.; Li, Y.; Xu, X.; Liang, B.; Wu, F.; Yang, X.; Ma, Q.; Yang, C.; Hu, X.; Liu, H.; et al. Antimicrobial resistance of Salmonella enterica serovar Typhimurium in Shanghai, China. Front. Microbiol. 2017, 8, 510. [CrossRef]

125. Wong, M.H.; Yan, M.; Chan, E.W.; Biao, K.; Chen, S. Emergence of clinical Salmonella enterica serovar Typhimurium isolates with concurrent resistance to ciprofloxacin, ceftriaxone, and azithromycin. Antimicrob. Agents Chemother. 2014, 58, 3752-3756. [CrossRef]

126. Al-Emran, H.M.; Heisig, A.; Dekker, D.; Adu-Sarkodie, Y.; Cruz Espinoza, L.M.; Panzner, U.; von Kalckreuth, V.; Marks, F.; Park, S.E.; Sarpong, N.; et al. Detection of a novel gyrB mutation associated with fluoroquinolone-nonsusceptible Salmonella enterica serovar Typhimurium isolated from a bloodstream infection in Ghana. Clin. Infect. Dis. 2016, 62, S47-S49. [CrossRef]

127. Casin, I.; Breuil, J.; Darchis, J.P.; Guelpa, C.; Collatz, E. Fluoroquinolone resistance linked to GyrA, GyrB, and ParC mutations in Salmonella enterica Typhimurium isolates in humans. Emerg. Infect. Dis. 2003, 9, 1455-1457. [CrossRef]

128. Zhang, W.H.; Zhang, C.Z.; Liu, Z.J.; Gu, X.X.; Li, W.; Yang, L.; Liu, Y.H.; Zeng, Z.L.; Jiang, H.X. In vitro development of ciprofloxacin resistance of Salmonella enterica serovars Typhimurium, Enteritidis, and Indiana isolates from food animals. Microb. Drug Resist. 2017, 23, 687-694. [CrossRef] [PubMed]

129. Chen, S.; Cui, S.; McDermott, P.F.; Zhao, S.; White, D.G.; Paulsen, I.; Meng, J. Contribution of target gene mutations and efflux to decreased susceptibility of Salmonella enterica serovar Typhimurium to fluoroquinolones and other antimicrobials. Antimicrob. Agents Chemother. 2007, 51, 535-542. [CrossRef] [PubMed]

130. Sun, Y.; Dai, M.; Hao, H.; Wang, Y.; Huang, L.; Almofti, Y.A.; Liu, Z.; Yuan, Z. The role of RamA on the development of ciprofloxacin resistance in Salmonella enterica serovar Typhimurium. PLoS ONE 2011, 6, e23471. [CrossRef] [PubMed]

131. de Toro, M.; Rojo-Bezares, B.; Vinue, L.; Undabeitia, E.; Torres, C.; Saenz, Y. In vivo selection of $a a c\left(6^{\prime}\right)-I b-c r$ and mutations in the gyrA gene in a clinical qnrS1-positive Salmonella enterica serovar Typhimurium DT104B strain recovered after fluoroquinolone treatment. J. Antimicrob. Chemother. 2010, 65, 1945-1949. [CrossRef] [PubMed]

132. Cernela, N.; Nuesch-Inderbinen, M.; Hachler, H.; Stephan, R. Antimicrobial resistance patterns and genotypes of Salmonella enterica serovar Hadar strains associated with human infections in Switzerland, 2005-2010. Epidemiol. Infect. 2014, 142, 84-89. [CrossRef]

133. Abgottspon, H.; Zurfluh, K.; Nuesch-Inderbinen, M.; Hachler, H.; Stephan, R. Quinolone resistance mechanisms in Salmonella enterica serovars Hadar, Kentucky, Virchow, Schwarzengrund, and 4,5,12:i:-, isolated from humans in Switzerland, and identification of a novel qnrD variant, qnrD2, in S. Hadar. Antimicrob Agents Chemother. 2014, 58, 3560-3563. [CrossRef]

134. Tamang, M.D.; Nam, H.-M.; Kim, A.; Lee, H.-S.; Kim, T.-S.; Kim, M.-J.; Jang, G.-C.; Jung, S.-C.; Lim, S.-K. Prevalence and mechanisms of quinolone resistance among selected nontyphoid Salmonella isolated from food animals and humans in Korea. Foodborne Pathog. Dis. 2011, 8, 1199-1206. [CrossRef]

135. Murgia, M.; Bouchrif, B.; Timinouni, M.; Al-Qahtani, A.; Al-Ahdal, M.N.; Cappuccinelli, P.; Rubino, S.; Paglietti, B. Antibiotic resistance determinants and genetic analysis of Salmonella enterica isolated from food in Morocco. Int. J. Food Microbiol. 2015, 215, 31-39. [CrossRef] 
136. Lindstedt, B.; Aas, L.; Kapperud, G. Geographically dependent distribution of gyrA gene mutations at codons 83 and 87 in Salmonella Hadar, and a novel codon 81 Gly to His mutation in Salmonella Enteritidis. Apmis 2004, 112, 165-171. [CrossRef]

137. Haugum, K.; Aas, L.; Lindstedt, B. Effect of quinolone antibiotics and chemicals on mutation types in Salmonella enterica serovars Enteritidis, Hadar and Virchow. J. Chin. Clin. Med. 2007, 2, 241-251.

138. Fiegen, U.; Klein, G.; de Jong, A.; Kehrenberg, C. Detection of a novel qnrB19-carrying plasmid variant mediating decreased fluoroquinolone susceptibility in Salmonella enterica serovar Hadar. Microb. Drug Resist. 2017, 23, 280-284. [CrossRef] [PubMed]

139. Le Hello, S.; Hendriksen, R.S.; Doublet, B.; Fisher, I.; Nielsen, E.M.; Whichard, J.M.; Bouchrif, B.; Fashae, K.; Granier, S.A.; Jourdan-Da Silva, N.; et al. International spread of an epidemic population of Salmonella enterica serotype Kentucky ST198 resistant to ciprofloxacin. J. Infect. Dis. 2011, 204, 675-684. [CrossRef] [PubMed]

140. Le Hello, S.; Bekhit, A.; Granier, S.A.; Barua, H.; Beutlich, J.; Zajac, M.; Munch, S.; Sintchenko, V.; Bouchrif, B.; Fashae, K.; et al. The global establishment of a highly-fluoroquinolone resistant Salmonella enterica serotype Kentucky ST198 strain. Front. Microbiol. 2013, 4, 395. [CrossRef] [PubMed]

141. Westrell, T.; Monnet, D.L.; Gossner, C.; Heuer, O.; Takkinen, J. Drug resistant Salmonella enterica serotype Kentucky in Europe. Lancet Infect. Dis. 2014, 14, 270-271. [CrossRef]

142. Haley, B.J.; Kim, S.W.; Pettengill, J.; Luo, Y.; Karns, J.S.; Van Kessel, J.A. Genomic and evolutionary analysis of two Salmonella enterica serovar Kentucky sequence types isolated from bovine and poultry sources in North America. PLoS ONE 2016, 11, e0161225. [CrossRef]

143. Mulvey, M.R.; Boyd, D.A.; Finley, R.; Fakharuddin, K.; Langner, S.; Allen, V.; Ang, L.; Bekal, S.; El Bailey, S.; Haldane, D.; et al. Ciprofloxacin resistant Salmonella enterica serovar Kentucky in Canada. Emerg. Infect. Dis. 2013, 19, 999-1001. [CrossRef]

144. Seiffert, S.N.; Perreten, V.; Johannes, S.; Droz, S.; Bodmer, T.; Endimiani, A. OXA-48 carbapenemase-producing Salmonella enterica serovar Kentucky isolate of sequence type 198 in a patient transferred from Libya to Switzerland. Antimicrob. Agents Chemother. 2014, 58, 2446-2449. [CrossRef]

145. Jeong, H.S.; Kim, J.A.; Shin, J.H.; Chang, C.L.; Jeong, J.; Cho, J.H.; Kim, M.N.; Kim, S.; Kim, Y.R.; Lee, C.H.; et al. Prevalence of plasmid mediated quinolone resistance and mutations in the gyrase and topoisomerase IV genes in Salmonella isolated from 12 tertiary-care hospitals in Korea. Microb. Drug Resist. 2011, 17, 551-557. [CrossRef]

146. Weill, F.X.; Bertrand, S.; Guesnier, F.; Baucheron, S.; Cloeckaert, A.; Grimont, P.A. Ciprofloxacin resistant Salmonella Kentucky in travelers. Emerg. Infect. Dis. 2006, 12, 1611-1612. [CrossRef]

147. Palomo, G.; Campos, M.J.; Ugarte, M.; Porrero, M.C.; Alonso, J.M.; Borge, C.; Vadillo, S.; Domínguez, L.; Quesada, A.; Píriz, S. Dissemination of antimicrobial-resistant clones of Salmonella enterica among domestic animals, wild animals, and humans. Foodborne Pathog. Dis. 2013, 10, 171-176. [CrossRef]

148. Wasyl, D.; Kern-Zdanowicz, I.; Domanska-Blicharz, K.; Zajac, M.; Hoszowski, A. High-level fluoroquinolone resistant Salmonella enterica serovar Kentucky ST198 epidemic clone with IncA/C conjugative plasmid carrying bla(CTX-M-25) gene. Vet. Microbiol. 2015, 175, 85-91. [CrossRef] [PubMed]

149. Jiang, H.X.; Song, L.; Liu, J.; Zhang, X.H.; Ren, Y.N.; Zhang, W.H.; Zhang, J.Y.; Liu, Y.H.; Webber, M.A.; Ogbolu, D.O.; et al. Multiple transmissible genes encoding fluoroquinolone and third-generation cephalosporin resistance co-located in non-typhoidal Salmonella isolated from food-producing animals in China. Int. J. Antimicrob. Agents 2014, 43, 242-247. [CrossRef]

150. Lu, Y.; Zhao, H.; Liu, Y.; Zhou, X.; Wang, J.; Liu, T.; Beier, R.C.; Hou, X. Characterization of quinolone resistance in Salmonella enterica serovar Indiana from chickens in China. Poult. Sci. 2015, 94, 454-460. [CrossRef] [PubMed]

151. Bai, L.; Zhao, J.; Gan, X.; Wang, J.; Zhang, X.; Cui, S.; Xia, S.; Hu, Y.; Yan, S.; Wang, J.; et al. Emergence and diversity of Salmonella enterica serovar Indiana isolates with concurrent resistance to ciprofloxacin and cefotaxime from patients and food-producing animals in China. Antimicrob. Agents Chemother. 2016, 60, 3365-3371. [CrossRef]

152. Bai, L.; Lan, R.; Zhang, X.; Cui, S.; Xu, J.; Guo, Y.; Li, F.; Zhang, D. Prevalence of Salmonella isolates from chicken and pig slaughterhouses and emergence of ciprofloxacin and cefotaxime co-resistant S. enterica serovar Indiana in Henan, China. PLoS ONE 2015, 10, e0144532. [CrossRef]

153. Lin, D.; Chen, K.; Wai-Chi Chan, E.; Chen, S. Increasing prevalence of ciprofloxacin-resistant foodborne Salmonella strains harboring multiple PMQR elements but not target gene mutations. Sci. Rep. 2015, 5, 14754. [CrossRef] [PubMed]

154. Gong, J.; Kelly, P.; Wang, C. Prevalence and antimicrobial resistance of Salmonella enterica serovar Indiana in China (1984-2016). Zoonoses Public Health 2017, 64, 239-251. [CrossRef]

155. Velhner, M.; Kozoderovic, G.; Grego, E.; Galic, N.; Stojanov, I.; Jelesic, Z.; Kehrenberg, C. Clonal spread of Salmonella enterica serovar Infantis in Serbia: Acquisition of mutations in the topoisomerase genes gyrA and parC leads to increased resistance to fluoroquinolones. Zoonoses Public Health 2014, 61, 364-370. [CrossRef]

156. Rahmani, M.; Peighambari, S.M.; Svendsen, C.A.; Cavaco, L.M.; Agerso, Y.; Hendriksen, R.S. Molecular clonality and antimicrobial resistance in Salmonella enterica serovars Enteritidis and Infantis from broilers in three Northern regions of Iran. BMC Vet. Res. 2013, 9, 66. [CrossRef]

157. Hauser, E.; Hebner, F.; Tietze, E.; Helmuth, R.; Junker, E.; Prager, R.; Schroeter, A.; Rabsch, W.; Fruth, A.; Malorny, B. Diversity of Salmonella enterica serovar Derby isolated from pig, pork and humans in Germany. Int. J. Food Microbiol. 2011, 151, 141-149. [CrossRef] [PubMed] 
158. Anjum, M.F.; Choudhary, S.; Morrison, V.; Snow, L.C.; Mafura, M.; Slickers, P.; Ehricht, R.; Woodward, M.J. Identifying antimicrobial resistance genes of human clinical relevance within Salmonella isolated from food animals in Great Britain. J. Antimicrob. Chemother. 2011, 66, 550-559. [CrossRef] [PubMed]

159. Bonardi, S.; Bassi, L.; Brindani, F.; D'Incau, M.; Barco, L.; Carra, E.; Pongolini, S. Prevalence, characterization and antimicrobial susceptibility of Salmonella enterica and Yersinia enterocolitica in pigs at slaughter in Italy. Int. J. Food Microbiol. 2013, 163, $248-257$. [CrossRef]

160. Wong, M.H.; Chen, S. First detection of oqxAB in Salmonella spp. isolated from food. Antimicrob. Agents Chemother. 2013, 57, 658-660. [CrossRef]

161. Deekshit, V.K.; Kumar, B.K.; Rai, P.; Karunasagar, I.; Karunasagar, I. Differential expression of virulence genes and role of $g y r A$ mutations in quinolone resistant and susceptible strains of Salmonella Weltevreden and Newport isolated from seafood. J. Appl. Microbiol. 2015, 119, 970-980. [CrossRef]

162. Cavaco, L.M.; Korsgaard, H.; Sorensen, G.; Aarestrup, F.M. Plasmid mediated quinolone resistance due to qnrB5 and qnrS1 genes in Salmonella enterica serovars Newport, Hadar and Saintpaul isolated from turkey meat in Denmark. J. Antimicrob. Chemother. 2008, 62, 632-634. [CrossRef] [PubMed]

163. Campbell, D.; Tagg, K.; Bicknese, A.; McCullough, A.; Chen, J.; Karp, B.E.; Folster, J.P. Identification and Characterization of Salmonella enterica Serotype Newport Isolates with Decreased Susceptibility to Ciprofloxacin in the United States. Antimicrob. Agents Chemother. 2018, 62, e00653-18. [CrossRef] [PubMed]

164. Bonalli, M.; Stephan, R.; Kappeli, U.; Cernela, N.; Adank, L.; Hachler, H. Salmonella enterica serotype Virchow associated with human infections in Switzerland: 2004-2009. BMC Infect. Dis. 2011, 11, 49. [CrossRef] [PubMed]

165. Clemente, L.; Correia, I.; Themudo, P.; Neto, I.; Canica, M.; Bernardo, F. Antimicrobial susceptibility of Salmonella enterica isolates from healthy breeder and broiler flocks in Portugal. Vet. J. 2014, 200, 276-281. [CrossRef]

166. Kim, J.H.; Cho, J.K.; Kim, K.S. Prevalence and characterization of plasmid mediated quinolone resistance genes in Salmonella isolated from poultry in Korea. Avian Pathol. 2013, 42, 221-229. [CrossRef]

167. Morgan-Linnell, S.K.; Becnel Boyd, L.; Steffen, D.; Zechiedrich, L. Mechanisms accounting for fluoroquinolone resistance in Escherichia coli clinical isolates. Antimicrob. Agents Chemother. 2009, 53, 235-241. [CrossRef] [PubMed]

168. Hooda, Y.; Sajib, M.S.I.; Rahman, H.; Luby, S.P.; Bondy-Denomy, J.; Santosham, M.; Andrews, J.R.; Saha, S.K.; Saha, S. Molecular mechanism of azithromycin resistance among typhoidal Salmonella strains in Bangladesh identified through passive pediatric surveillance. PLoS Negl. Trop. Dis. 2019, 13, e0007868. [CrossRef] [PubMed]

169. Sharma, P.; Kumari, B.; Dahiya, S.; Kulsum, U.; Kumar, S.; Manral, N.; Pandey, S.; Kaur, P.; Sood, S.; Das, B.K.; et al. Azithromycin resistance mechanisms in typhoidal salmonellae in India: A 25 years analysis. Indian J. Med. Res. 2019, 149, 404-411.

170. Fu, Y.; Xu, X.; Zhang, L.; Xiong, Z.; Ma, Y.; Wei, Y.; Chen, Z.; Bai, J.; Liao, M.; Zhang, J. Fourth Generation Cephalosporin Resistance Among Salmonella enterica Serovar Enteritidis Isolates in Shanghai, China Conferred by bla CTX-M-55 Harboring Plasmids. Front. Microbiol. 2020, 11, 910. [CrossRef] [PubMed]

171. Feger, G.; Angelov, B.; Angelova, A. Prediction of Amphiphilic Cell-Penetrating Peptide Building Blocks from Protein-Derived Amino Acid Sequences for Engineering of Drug Delivery Nanoassemblies. J. Phys. Chem. B 2020, 124, 4069-4078. [CrossRef] [PubMed]

172. Tariq, A.; Sana, M.; Shaheen, A.; Ismat, F.; Mahboob, S.; Rauf, W.; Mirza, O.; Iqbal, M.; Rahman, M. Restraining the multidrug efflux transporter STY4874 of Salmonella Typhi by reserpine and plant extracts. Lett. Appl. Microbiol. 2019, 69, 161-167. [CrossRef] [PubMed] 